\title{
Tailor-Made, Linear, and "Comb-Like" Polyester-Based Copolymers: Synthesis, Characterization, and Thermal Behavior of Potential 3D-Printing/Electrospinning Candidates
}

\author{
Franco L. Redondo, ${ }^{1,2}$ Mario D. Ninago ${ }^{D},{ }^{3,4}$ Augusto G. O. de Freitas, ${ }^{5}$ \\ Cristiano Giacomelli, ${ }^{6}$ Andrés E. Ciolino $\mathbb{D}^{1,2}$ and Marcelo A. Villar ${ }^{1,2}$ \\ ${ }^{1}$ Planta Piloto de Ingeniería Química, PLAPIQUI (UNS-CONICET), CP: 8000, Camino "La Carrindanga" Km 7, Bahía Blanca, \\ Buenos Aires, Argentina \\ ${ }^{2}$ Departamento de Ingeniería Química, Universidad Nacional del Sur (UNS), CP: 8000, Av. Alem 1253, Bahía Blanca, \\ Buenos Aires, Argentina \\ ${ }^{3}$ Departamento de Ingeniería Química, Facultad de Ciencias Aplicadas a la Industria (FCAI), \\ Universidad Nacional de Cuyo (UNCuyo), CP: 5600, Bernardo de Irigoyen 375, San Rafael, Mendoza, Argentina \\ ${ }^{4}$ Consejo Nacional de Investigaciones Científicas y Técnicas (CONICET), Godoy Cruz, \\ 2290 Ciudad Autónoma de Buenos Aires, Argentina \\ ${ }^{5}$ Universidade Federal do Pampa, Unipampa (97650-000), Itaqui, RS, Brazil \\ ${ }^{6}$ Departamento de Química, Universidade Federal de Santa María, 97105-900 Santa María, RS, Brazil
}

Correspondence should be addressed to Mario D. Ninago; mninago@plapiqui.edu.ar

Received 11 June 2018; Revised 16 August 2018; Accepted 2 September 2018; Published 21 October 2018

Academic Editor: Cornelia Vasile

Copyright (c) 2018 Franco L. Redondo et al. This is an open access article distributed under the Creative Commons Attribution License, which permits unrestricted use, distribution, and reproduction in any medium, provided the original work is properly cited.

\begin{abstract}
Tailor-made, linear, and "comb-like" poly( $\varepsilon$-caprolactone)-based copolymers were synthesized by employing a combination of controlled polymerization techniques. Poly(dimethylsiloxane-block- $\varepsilon$-caprolactone) copolymers (SCL\#) were synthesized by a combination of anionic and ring-opening polymerization (ROP), whereas "comb-like" poly(hydroxyethylmethacrylate-co-

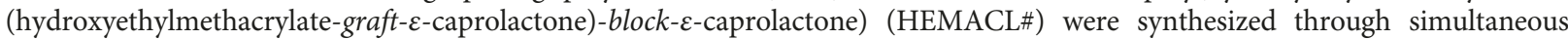
ROP and reversible addition fragmentation chain transfer (RAFT) polymerization. Copolymers were characterized by hydrogen nuclear magnetic resonance $\left({ }^{1} \mathrm{H}-\mathrm{NMR}\right)$, size exclusion chromatography (SEC), and Fourier transform infrared (FTIR) spectroscopy. All polymers exhibited narrow molar masses distributions $\left(M_{\mathrm{w}} / M_{\mathrm{n}}<1.54\right)$, and their thermal properties were analyzed by isothermal crystallization kinetics (Avrami's theory, by using differential scanning calorimetry (DSC)) and by employing modulated thermogravimetric analysis (MTGA). The macromolecular structure exerts a noticeable effect on the PCL block behavior when compared to the PCL homopolymer, at least for the temperature range studied (16-24 $\left.{ }^{\circ} \mathrm{C}\right)$ : less differences in thermal properties were observed for linear block copolymers, whereas for "comb-like" graft copolymers their final crystallization capacity strongly depends on the presence of branches. For both sets of copolymers, the decrease in the resulting melting temperatures and the increase in the half-life crystallization time values might be useful processing parameters, particularly if these copolymers are planned for using as an alternative source of 3D printing or electrospinning materials.
\end{abstract}

\section{Introduction}

During the last decades, the development of new polymerization techniques (which involve less sophisticated procedures from a practical point of view) has noticeably increased the potential of polymer materials to expand their uses [1]. Complex macromolecular structures are now easily achieved, and a broad range of applications for new polymeric materials can be proposed at levels scarcely envisioned a few decades ago $[2,3]$. Reversible deactivation radical polymerization 
(RDRP) techniques, such as atom transfer polymerization (ATRP), nitroxide-mediated polymerization (NMP), and reversible addition-fragmentation chain-transfer (RAFT) polymerization, are now well-established, and their uses in the synthesis of macromolecules are widely employed in synthetic laboratories worldwide.

For a long time, graft and block copolymers have received the attention of polymer scientists due to their attractive macromolecular characteristics and properties. This interest lies on the combination of thermodynamically incompatible macromolecular species linked together, which imposes restrictions regarding their properties and final applications. Moreover, the processability of these materials is a crucial point that will justify their further uses. In such a sense, many processing parameters such as viscosity-temperature dependence, glass-transition temperature, thermal stability, and melting temperature of semicrystalline blocks or segments are critical to decide whether or not using them [4].

Recent developments regarding biocompatible materials have enabled 3D bioprinting of functional living tissues, mainly applied to regenerative medicine to address the need for organ transplantation [5-7]. In this aspect, 3D bioprinting materials are limited to biocompatible synthetic and natural polymers, such as targeted synthetic diblock copolymers, sodium alginate, chitosan, and acrylate-based polymers, among others [6]. In fact, many ink formulations or 3Dprintable materials for biomedical purposes are made from copolymers or from the combination of complex macromolecular structures, which can be obtained by adjusting wellknown polymerization pathways $[8,9]$.

Another area of interest in which biocompatible materials deserve special interest is electrospinning. By using this technique, the preparation of nanofibers from different materials (synthetic or natural polymers, composites, ceramics, and even inorganic oxides) can be strategically targeted in order to obtain specific properties [10]. Medical studies have used this technique to design nanofiber for drug delivery systems as well as scaffolds for tissue engineering [11]. The processability of the polymeric materials, their solubility behavior, and their concentration are some of the parameters of interest to produce targeted nanofiber mats or meshes.

Poly( $\varepsilon$-caprolactone) (PCL) is an aliphatic and hydrophobic polyester with good biodegradable and mechanical properties. This semicrystalline polymer has a relative low melting temperature $\left(T_{\mathrm{m}} \sim 60^{\circ} \mathrm{C}\right)$ and an appropriate glass-transition temperature for technical applications $\left(T_{\mathrm{g}} \sim-60^{\circ} \mathrm{C}\right)$. In addition, the aliphatic nature of the main chain explains its compatibility with a large variety of polymers [12], whereas its lack of toxicity is a strong reason to use it as an excellent candidate in a wide range of biomedical applications such as long-term implantable devices, scaffolds for tissue growth, and drug delivery systems, among others [13-15]. PCL can be easily synthesized by the ring-opening polymerization (ROP) of $\varepsilon$-caprolactone $(\varepsilon$-CL) monomer promoted by suitable catalysts, such as tin(II) octanoate and a hydroxyl initiator [12]. Regarding its use as 3Dprinting material, it has been reported that PCL nanoparticles have been used as ink that can be printed on a bioadhesive film for the local treatment of cervical cancer, corroborating that the printing process does not disrupt the structure of nanoparticles nor inclusion complexes [16].

Poly(2-hydryoxyethyl methacrylate) (PHEMA) is another biocompatible polymer, which is widely employed to produce hydrogel materials for ocular devices and soft contact lens [17]. These applications are possible due to the hydrophilicity of the hydroxyl moiety, which imposes to PHEMA-based hydrogel physical properties that resemble those of living tissue: high water content, soft and rubbery consistency, and low interfacial tension [18]. HEMA monomer can be copolymerized with other biocompatible monomers (such as $\varepsilon$-CL), by employing conventional freeradical polymerization mechanisms or RDRP techniques. Particularly, PCL chains grafted onto the PHEMA backbone can be obtained by RAFT polymerization [19-22], since this method allows tuning the molar masses distribution and the polydispersity indexes of the resulting complex macromolecular architectures like stars, blocks, or graft copolymers without needing sophisticated experimental procedures [23].

Poly(siloxanes) belong to the family of organic/inorganic materials, such as poly(phosphazenes), and they can be obtained from cyclic siloxane monomers. Particularly, poly(dimethylsiloxane) (PDMS) is the homopolymer made from siloxane cycles whose chemical structure is $\left[-\left(\mathrm{CH}_{3}\right)_{2} \mathrm{SiO}-\right]_{n}$, in which $n$ denotes 3 or 4 repeating units. PDMS has unique properties such as high thermal and electric stability, and low glass-transition temperature $\left(T_{\mathrm{g}} \sim-123^{\circ} \mathrm{C}\right)$. Besides, PDMS has no chemical reactivity and displays a marked hydrophobicity and excellent physiological compatibility [24, 25]. The conventional synthesis of PDMS is carried out by hydrolysis and condensation reactions of dimethyldichlorosilanes in alkaline or acid media, by producing cyclic and linear polymers without a good control of the homogeneity [26]. A better control of PDMS molecular parameters can be achieved by using anionic ROP of cyclic siloxanes [27-29]. Although PDMS and its derivatives are widely employed in technical applications, their use as 3D-printing materials has been proved challenging due to poor mechanical properties and need for supporting during the process [30, 31]. Consequently, the searching of likely alternatives for these materials constitutes an area of broad interest.

In previous papers, we have reported the synthesis of PCL-based copolymers by employing controlled polymerization techniques $[27,28,32]$. In an effort to expand the understanding of their physicochemical characteristics, the aim of this work was focused on the thermal behavior (at moderate temperatures) of two block copolymers series based on $\varepsilon$-CL monomer. In this sense, poly(dimethylsiloxane-block- $\varepsilon$ caprolactone), P (DMS- $b-\varepsilon-C L)$, poly(hydroxyethylmethacrylate-co-(hydroxyethylmethacrylate-graft- $\varepsilon$-caprolactone)-

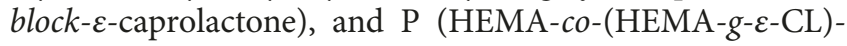
$b-\varepsilon-\mathrm{CL})$ copolymers were synthesized by combining anionic, ROP, and RAFT polymerizations. Besides synthesis, the work is focused on the crystallization and thermal behavior of these polyester-based copolymers, both containing biocompatible blocks.

PCL has been employed as 3D bioprinting material, and it is expected that biocompatible block copolymers based 
on PCL might expand its applications in the field. As it is known, in material extrusion techniques (such as 3Dprinting or electrospinning devices), polymers are directly pushed out through a nozzle when a constant pressure is applied. The extruded material is deposited at a constant speed and fully solidifies on the substrate after coming out from the nozzle [6]. In this sense, the understanding of the crystallization behavior of branched and linear copolymers based on PCL at temperatures lower than that corresponding to the linear homopolymer could lead to changes in processing parameters, especially if they are targeted for specific purposes. In such a sense, the thermal stabilities of the studied polymers were analyzed, and Avrami's isothermal crystallization model was employed to calculate kinetic parameters from the crystallization process [32-36]. It is inferred that data obtained from this analysis will provide useful information for further applications, particularly if these materials or combinations of them are planned for using as potential inks in $3 \mathrm{D}$-printing or electrospinning devices $[5-7,16]$.

\section{Materials and Methods}

2.1. Materials. Hexamethyl(cyclotrisiloxane) monomer $\left(\mathrm{D}_{3}\right.$, Sigma-Aldrich) was purified according to conventional routines for high-vacuum anionic polymerization techniques. The initiator employed for anionic $\mathrm{D}_{3}$ polymerization was sec-butyllithium (sec- $\left.\mathrm{Bu}^{-} \mathrm{Li}^{+}\right)$, freshly prepared in vacuum from sec-butyl chloride (Fluka) and lithium metal (Fluka) by following conventional synthetic procedures already reported [37]. Tetrahydrofuran (THF, Ciccarelli) was used as polymerization promoter, whereas cyclohexane (Dorwill) and degassed methanol (Química Industrial) were used as solvent and protonating agent, respectively [38-41].

$\varepsilon$-Caprolactone monomer ( $\varepsilon$-CL, Aldrich) was employed as received. Its polymerization was performed by using tin(II) octanoate $\left(\mathrm{Sn}(\mathrm{Oct})_{2}\right.$, Aldrich) as catalyst, following the procedure previously reported by Satti et al. [42]. 2Hydroxyethyl(methacrylate) (HEMA, Aldrich), diphenyl phosphate (DPP), 1,1'-azobis(cyclohexanecarbonitrile) (Vazo catalyst 88, Aldrich, 98\%), toluene (Aldrich), methanol (Química Industrial), dimethylformamide (DMF), chloroform (Aldrich), deuterated chloroform $\left(\mathrm{CDCl}_{3}\right)$, and petroleum ether were used without any further purification. 2(Benzylsulfanylthiocarbonylsulfanyl)ethanol (BSTSE, chain transfer agent for RAFT polymerization and hydroxyl initiator for ROP) was prepared following a one-pot procedure, purified by column chromatography on silica using petroleum ether as eluent and recrystallized under cold conditions, as it was previously described [20, 43, 44].

2.2. Synthesis of $P$ (DMS-b-e-CL) Block Copolymers (SCL\#). Polymerizations were carried out in two steps. First, a model poly(dimethylsiloxane) hydroxyl-ended homopolymer (PDMS-OH) was synthesized by employing anionic polymerization and hand-made polymerization apparatuses (glass-blowing techniques), by a vacuum manifold (VM), and by following the methodology reported in our previous works [3, 39, 40]. Briefly, the reactor was attached to the VM and checked for pinholes. Then, the stopcock was closed and approximately $5 \mathrm{~mL}$ of commercial $n$-butyllithium solution in hexane $\left(n-\mathrm{Bu}^{-} \mathrm{Li}^{+} 2 \mathrm{M}\right.$, Aldrich) was injected into the purge section flask. After that, the stopcock of the VM was opened and the apparatus was pumped during 30 minutes in order to remove traces of hexane and air inside. Then, the reaction solvent was distilled from a collection flask already attached to the VM. After two freezing-thawing cycles, the apparatus was removed from the VM by heat-sealing, and it was washed with the diluted $n-\mathrm{Bu}^{-} \mathrm{Li}^{+}$solution inside. After washing, the solvent was distilled from purge section to the reactor, and once distillation was completed, the purge section was removed by heat-sealing procedures, leaving the clean reactor ready for polymerization. Then, the $\mathrm{D}_{3}$ monomer was poured into the reactor flask, followed by the addition of $\sec -\mathrm{Bu}^{-} \mathrm{Li}^{+}$. The reaction was left to proceed at room temperature during $\sim 20$ hours [39]. Finally, THF was added and $\mathrm{D}_{3}$ polymerization was left to proceed, at room temperature, during 20 hours. The reaction was finished by the addition of well-degassed methanol. The resulting PDMS was precipitated in cold methanol, traces of solvents were removed by employing a roto-evaporator $\left(\sim 60^{\circ} \mathrm{C}\right)$, and the final product was kept in vacuum until constant weight.

Copolymerization of PDMS-OH with $\varepsilon$-CL monomer was carried out in a specially designed Schlenk-type reactor by following the methodology already published [42-44]. In this sense, copolymers with a chemical composition ranging from low to intermediate PCL content were obtained by ROP of cyclic monomer. Copolymerization was performed under nitrogen atmosphere, employing degassed toluene as reaction solvent and a catalyst/PDMS-OH ratio of 0.5 . Reactions were carried out at $\sim 100-110^{\circ} \mathrm{C}$ during $24 \mathrm{~h}$. The resulting copolymers were precipitated in cold methanol, filtered, and vacuum-dried, at $20^{\circ} \mathrm{C}$, until constant weight. Since in this synthetic procedure the amount of $\varepsilon$-CL monomer was adjusted in each reaction, $\mathrm{P}$ (DMS- $b-\varepsilon-\mathrm{CL}$ ) copolymers were labelled as SCL\#, in which \# refers to PCL content from low (1) to high (4) wt\%.

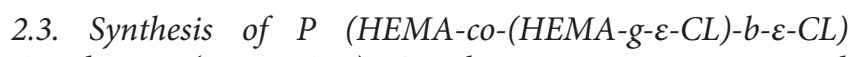
Copolymers (HEMACL\#). Copolymerizations were carried out in a one-pot procedure through a combination of simultaneous RAFT and ROP polymerizations, by following a methodology already published [28]. BSTSE, HEMA and $\varepsilon$ CL monomers, Vazo-88 radical initiator, dry toluene, and DMF were placed in a dry Schlenk flask equipped with a stirrer. The tube was closed, subjected to three freezepump-thaw cycles in the VM, and subsequently backfilled with nitrogen gas. The ROP catalyst DPP was then added under gentle nitrogen flow. Subsequently, the flask was closed and immediately immersed in an oil bath settled at $100^{\circ} \mathrm{C}$ to promote the simultaneous copolymerization reaction. The reaction was left to proceed during 24,2 , or $1 \mathrm{~h}$, and the final product was precipitated in cold methanol and dried in vacuum until constant weight [27, 28]. Since in this synthetic procedure the amount of grafted chains depends on the reaction time, P (HEMA-co-(HEMA- $g$ - $\varepsilon$ CL) $b-\varepsilon-\mathrm{CL}$ ) copolymers were labelled as HEMACL\#, in which \# denotes low (1) to high (3) reaction times. 


\subsection{Characterization}

2.4.1. Fourier Transform Infrared Spectroscopy (FTIR). Fourier transform infrared (FTIR) spectroscopy spectra of selected samples were obtained on a Nicolet ${ }^{\circledR}$ FTIR 520 spectrometer. Cast films from diluted solutions of the samples ( $1 \mathrm{wt} \%$ in THF) were obtained onto $\mathrm{NaCl}$ windows. FTIR spectra were recorded at $4 \mathrm{~cm}^{-1}$ resolution, over the $4000-$ $400 \mathrm{~cm}^{-1}$ range, 64 scans, and dried air as background.

2.4.2. Nuclear Magnetic Resonance $\left({ }^{1} \mathrm{H}-\mathrm{NMR}\right) .{ }^{1} \mathrm{H}-\mathrm{NMR}$ spectra of SCL\# copolymers were recorded on a Bruker ${ }^{\circledR}$ $300 \mathrm{MHz}$ instrument, by using deuterated chloroform $\left(\mathrm{CDCl}_{3}\right.$, Aldrich) as solvent. About 5-10 mg of sample was diluted directly in the NMR tubes, at room temperature. The chemical composition of synthesized copolymers was obtained by using the values of integrated areas from characteristic ${ }^{1} \mathrm{H}$ signals of each block. For HEMACL\# copolymers, ${ }^{1} \mathrm{H}-\mathrm{NMR}$ spectra were acquired using an Avance DPX-400 spectrometer ( $400 \mathrm{MHz}$ for $\mathrm{H}, 100 \mathrm{MHz}$ for $\mathrm{C}$ ). The spectra were obtained by dissolving a small quantity of the polymer sample $(\sim 10 \mathrm{mg})$, at room temperature, by using $\mathrm{CDCl}_{3}$ as solvent.

2.4.3. Size Exclusion Chromatography (SEC). SCL\# samples were characterized by SEC on a system built with a Waters ${ }^{\circledR}$ 515 HPLC pump and a Waters ${ }^{\circledR}$ model 410 differential refractometer, equipped with three mixed-bed PLgel linear columns and a precolumn with $5 \mu \mathrm{m}$ bead size (PLgel). Elution solvent was toluene (Aldrich), flowing at a rate of $1 \mathrm{~mL} \mathrm{~min}^{-1}$ at room temperature. Injection volume was $200 \mu \mathrm{L}$, and PS standards were used for calibration. MarkHouwink calibration constants used were $K_{\mathrm{PS}}=0.012 \mathrm{~mL}$ $\mathrm{g}^{-1}, \alpha_{\text {PS }}=0.71$ and $K_{\text {PDMS }}=0.0136 \mathrm{~mL} \mathrm{~g}^{-1}, \alpha_{\text {PDMS }}=0.69$ for PDMS $[32,45]$. SCL\# were also analyzed by employing the same equipment by using THF (Ciccarelli) as solvent in order to distinguish PCL blocks in the resulting copolymers. In this case, the Mark-Houwink calibration constants used for PCL were $K_{\mathrm{PCL}}=1.395 \times 10^{-4} \mathrm{~mL} \mathrm{~g}^{-1}$ and $\alpha_{\mathrm{PCL}}=0.786$ [46]. For HEMACL\# samples, toluene was used as solvent employing the aforementioned equipment. Mark-Houwink constants employed for PCL were $K_{\mathrm{PCL}}=0.01298 \mathrm{~mL} \mathrm{~g}^{-1}$, $\alpha_{\text {PCL }}=0.828$ [47].

2.4.4. Differential Scanning Calorimetry (DSC). Thermal analysis was performed by employing DSC Pyris 1 PerkinElmer ${ }^{\circledR}$ equipment. Samples were measured under He atmosphere, by using approximately $10 \mathrm{mg}$ of each copolymer. For SCL\# copolymers, samples were heated from -90 to $100^{\circ} \mathrm{C}$. Then, they were kept at $100^{\circ} \mathrm{C}$ during 5 minutes in order to avoid the influence of the previous thermal history. After cooling at $10^{\circ} \mathrm{C} \mathrm{min}^{-1}$, they were heated again from -90 to $100^{\circ} \mathrm{C}$ at a heating rate of $10^{\circ} \mathrm{C} \mathrm{min}{ }^{-1}$. From the second heating, glass-transition temperature $\left(T_{\mathrm{g}}\right)$ of PCL block and melting temperature $\left(T_{\mathrm{m}}\right)$ of PDMS and PCL blocks were determined. For HEMACL\# copolymers, samples were heated from 15 to $100^{\circ} \mathrm{C}$. Then, they were kept at $100^{\circ} \mathrm{C}$ during 5 minutes in order to avoid the influence of the previous thermal history. After cooling at $10^{\circ} \mathrm{C} \mathrm{min}^{-1}$, they were heated again from 15 to $100^{\circ} \mathrm{C}$ at a heating rate of $10^{\circ} \mathrm{C} \mathrm{min}{ }^{-1}$. From the second heating, $T_{\mathrm{m}}$ of PCL blocks and $T_{\mathrm{g}}$ of PHEMA blocks were determined.

2.4.5. Isothermal Crystallization Tests. Isothermal crystallization tests were carried out by using the above-mentioned equipment and by employing sequential steps described as follows: first, samples were heated from 15 to $90^{\circ} \mathrm{C}$ at $10^{\circ} \mathrm{C} \mathrm{min}^{-1}$. Then, they were kept at $90^{\circ} \mathrm{C}$ during $5 \mathrm{~min}$ and rapidly cooled $\left(60^{\circ} \mathrm{C} \mathrm{min}{ }^{-1}\right)$ to selected crystallization temperatures $\left(T_{c}\right)$ according to the methodology reported in previous works [32, 34, 48, 49]. Isothermal crystallization tests were carried out for temperatures between 16 and $24^{\circ} \mathrm{C}$, by using $2^{\circ} \mathrm{C}$ steps. Finally, after isothermal crystallization, samples were heated up to $90^{\circ} \mathrm{C}\left(10^{\circ} \mathrm{C} \mathrm{min}{ }^{-1}\right)$ in order to determine the heat of fusion $\left(\Delta H_{\mathrm{f}}\right)$. In all cases, the heat of crystallization $\left(\Delta H_{c}\right)$ as a function of time $(t)$ was recorded at different isothermal $T_{c}$.

2.4.6. Modulated Thermogravimetric Analysis (MTGA). Thermal stability was analyzed by using Discovery TA Instruments TGA 5500 equipment. Tests were carried out under nitrogen atmosphere, with a flow rate of $25 \mathrm{~mL} \mathrm{~min}^{-1}$ and $2^{\circ} \mathrm{C} \mathrm{min}^{-1}$ heating rate, in the $40-700^{\circ} \mathrm{C}$ range. Weight loss curves as a function of temperature were registered. Besides, modulated thermogravimetry assays were performed to obtain continuous kinetic information regarding decomposition reactions. MTGA tests were made by using an oscillatory temperature program. Samples were analyzed by triplicate, and the resulting data (three values average) are informed with their associated standard deviation. The results obtained were compared with those for linear PCL in order to analyze the influence of the neighbor block and random branches on the thermal stability of the resulting copolymers.

\section{Results and Discussion}

SCL\# copolymers were synthesized by combining classical anionic polymerization followed by ROP. PDMS-OH homopolymer was employed as macroinitiator for ROP of $\varepsilon$-CL monomer. Using this synthetic pathway, four different copolymers from low to intermediate PCL content were obtained. Scheme 1 shows the reaction pathways employed for this purpose.

Regarding HEMACL\#, these copolymers were synthesized through a combination of RAFT and ROP polymerizations in a one-pot reaction, as it was reported in our previous work [28]. Scheme 2 shows the reaction pathway employed for this purpose, in which ROP of $\varepsilon$-CL simultaneously takes place from the hydroxyl moieties from HEMA monomer and BSTSE RAFT agent, respectively.

The reaction proposed in Scheme 2 produces graft PCL branches in the resulting HEMACL\# copolymers, whose distribution will strongly depend on reaction time $(2,1$, and 24 hours for HEMACL1, HEMACL2, and HEMACL3, respectively). The macromolecular architecture obtained can be thought as a "densed and/or un-densed comblike copolymers," in which the main skeleton is a block 


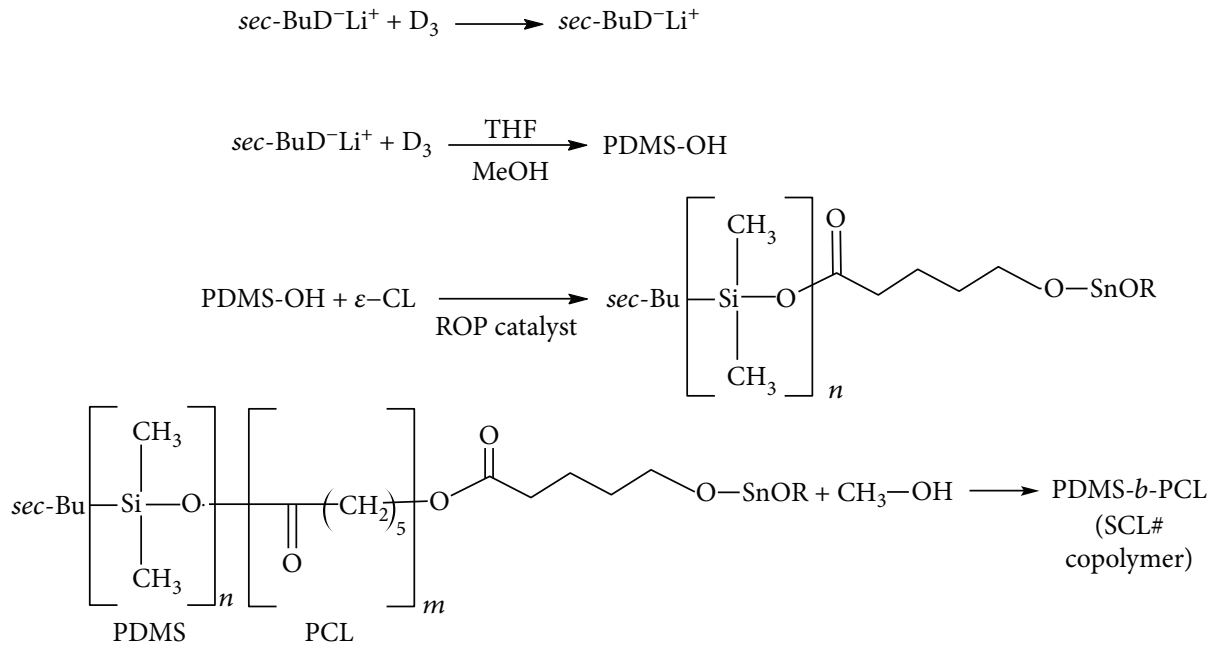

SCHEME 1: Synthesis of SCL\# copolymers.

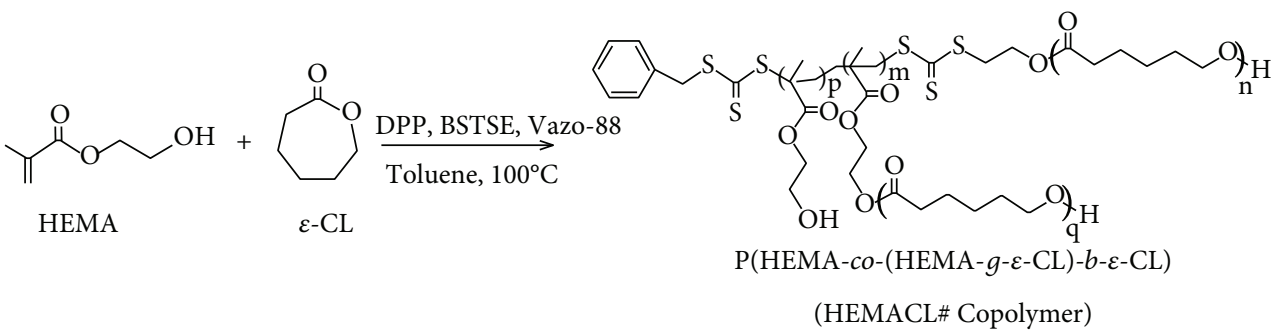

Scheme 2: Synthesis of HEMACL\# copolymers.

copolymer based on HEMA and $\varepsilon$-CL, and teeth are random PCL blocks pending from HEMA monomer units. Consequently, HEMACL\# copolymers can be thought as "pseudo" branched PCLs.

According to chemical characterization, Figure 1 shows selected FTIR spectra from PDMS-OH and PCL homopolymers, as well as SCL1 and HEMACL3 copolymers. PDMS$\mathrm{OH}$ and PCL spectra were shifted in the transmittance axis in order to display the common absorption bands that appear in both copolymers. The broad absorption band at 3900$3200 \mathrm{~cm}^{-1}$ is associated with the stretching of the $-\mathrm{OH}$ group in PDMS-OH homopolymer. The spectrum of this polymer also shows an absorption band at $2963 \mathrm{~cm}^{-1}$ associated to the vibration bonds of $\mathrm{C}-\mathrm{H}$ attached to $\mathrm{Si}$ atoms [50]. At $1261 \mathrm{~cm}^{-1}$, the out-of-phase vibrations of $\mathrm{Si}-\left(\mathrm{CH}_{3}\right)_{2}$ and $\mathrm{O}-\mathrm{Si}-\mathrm{OR}$ are also detected [1]. Besides, at $1093 \mathrm{~cm}^{-1}$ and $1024 \mathrm{~cm}^{-1}$, absorption bands associated to the vibration of $\mathrm{Si}-\mathrm{O}-\mathrm{Si}$ and $\mathrm{C}-\mathrm{Si}-\mathrm{C}$ bonds, respectively, can be observed $[3,32]$. The PCL spectrum shows an absorption band at $1724 \mathrm{~cm}^{-1}$ associated to the stretching vibrations from carbonyl $>\mathrm{C}=\mathrm{O}$ groups, as well as at $1240 \mathrm{~cm}^{-1}$ (vibrations of $\mathrm{O}-\mathrm{C}=\mathrm{O})[33,42]$. On the other hand, FTIR spectra from SCL1 and HEMACL3 copolymers exhibit the typical absorption bands from their constitutive blocks, as it was reported by several authors $[32,42,51]$. In this sense, PCL absorption signals were detected at $1724 \mathrm{~cm}^{-1}$ and $1240 \mathrm{~cm}^{-1}$. In addition, for HEMACL\# copolymer a strong stretching band at

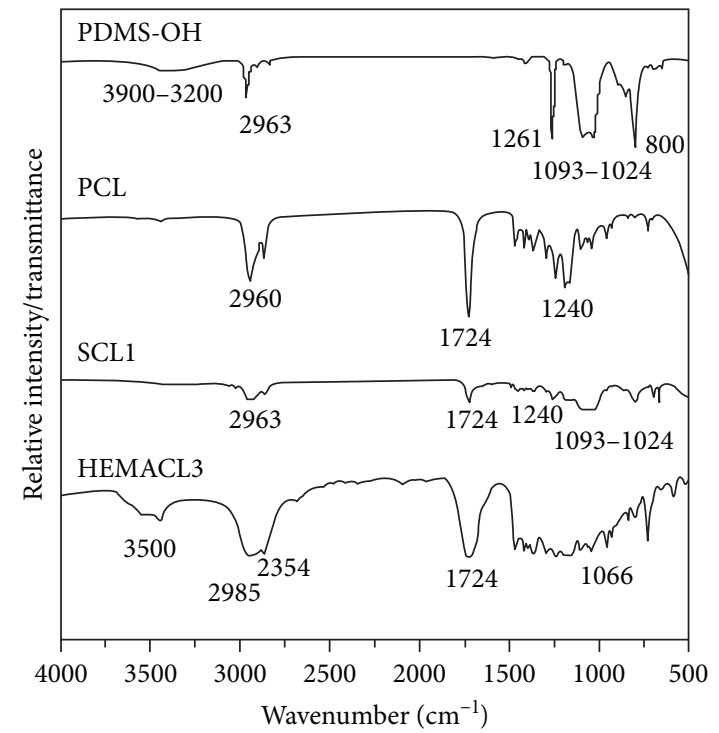

FIgURe 1: FTIR spectra of PDMS-OH, linear PCL, P (DMS- $b-\varepsilon-C L)$ SCL1, and P (HEMA-co-(HEMA- $g$ - $\varepsilon$-CL)- $b-\varepsilon-C L)$ HEMACL3.

$3500-3100 \mathrm{~cm}^{-1}$ is observed, which should be assigned to $-\mathrm{OH}$ vibration as it was already reported by Sahiner and Demirci [51]. Besides, aliphatic C-H stretching bands at $2985 \mathrm{~cm}^{-1}$ and $2854 \mathrm{~cm}^{-1}$ are also detected [51], together 

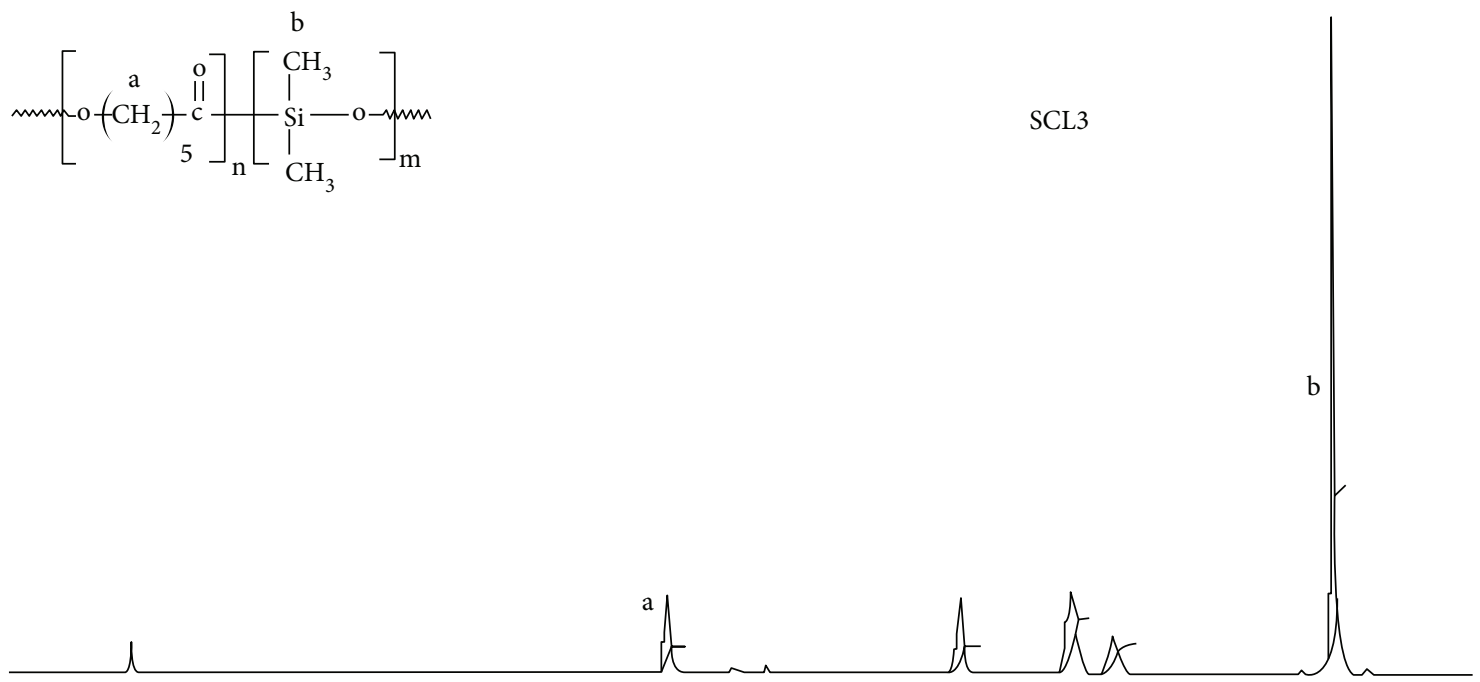

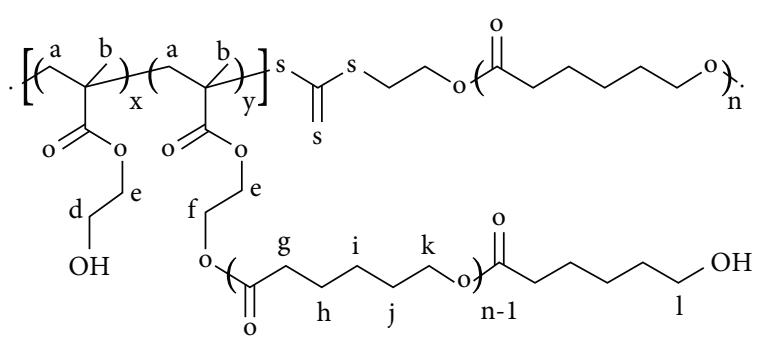

HEMACL2

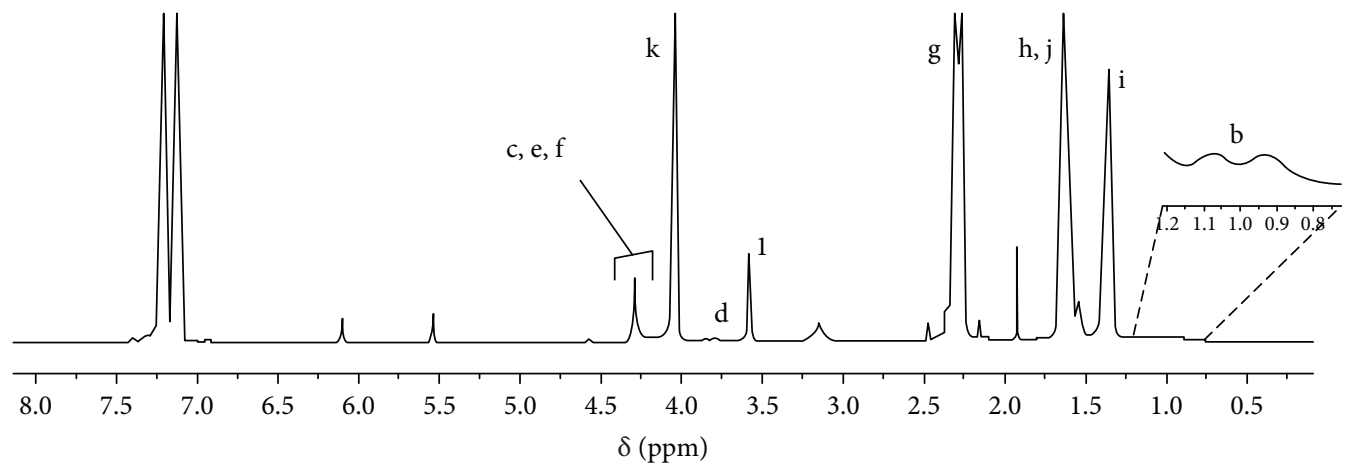

FIgURE 2: ${ }^{1} \mathrm{H}-\mathrm{NMR}$ spectra of P (DMS- $b$ - $\varepsilon$-CL) SCL3 and P (HEMA-co-(HEMA- $g$ - $\varepsilon$-CL)- $b$ - $\varepsilon$-CL) HEMACL2 copolymers.

with absorption bands assigned to the transfer agent BSTSE at $1066 \mathrm{~cm}^{-1}[27,28]$. Figure 2 shows typical ${ }^{1} \mathrm{H}-\mathrm{NMR}$ spectra from SCL3 and HEMACL2 copolymers. The characteristic signals from constitutive blocks and the corresponding $\delta$ (ppm) assignments are displayed in the spectra. According to the NMR spectrum provided in Figure 2 for HEMACL2, the difference between grafted and ungrafted HEMA units is the $d$ and $f$ signals that belong to methylene units attached to free $-\mathrm{OH}$ groups $(\mathrm{d})$ or reacted $-\mathrm{OH}$ groups by esterification (f).

For SEC analysis, Figure 3 displays SEC chromatograms for PDMS-OH macroinitiator and SCL4 copolymer (toluene as solvent). The PDMS homopolymer was a model polymer, with a low polydispersity index $\left(M_{\mathrm{n}}=13,000 \mathrm{~g} \mathrm{~mol}^{-1}, M_{\mathrm{w}} /\right.$ $M_{\mathrm{n}}=1.07$, Table 1). On the other hand, the SCL4 copolymer shows an increase in $M_{\mathrm{n}}$ value $\left(M_{\mathrm{n}}=65,000 \mathrm{~g} \mathrm{~mol}^{-1}\right)$, with $M_{\mathrm{w}} / M_{\mathrm{n}}=1.54$ (Table 1). For the other copolymers, $M_{\mathrm{n}}$ values show an increasing trend as soon as $w_{\mathrm{PCL}}$ increases, and $M_{\mathrm{w}} / M_{\mathrm{n}}$ indexes display values between 1.36 (SCL1) and 1.45 (SCL3). Although $M_{\mathrm{w}} / M_{\mathrm{n}}$ values for SCL\# seem to be far from model samples, they are quite good by taking into account that $\varepsilon$-CL monomer was employed as received in order to simplify synthetic procedures. As it can be seen from Table 1 and Figure 3, SCL4 displays a broad molar masses distribution (when compared to PDMS-OH) and a small shoulder at higher molar masses values. These facts might be assigned to the presence of water or hydroxyl impurities from commercial $\mathcal{E}$-CL monomer as well as inaccuracies in the refractive index detector for PCL blocks for the solvent employed (toluene). The presence of water or hydroxyl impurities might lead to uncontrolled ROP due to the formation of stable tin alkoxides [52, 53], whereas the use of toluene as solvent results in a less defined chromatogram when compared to that from the initial 


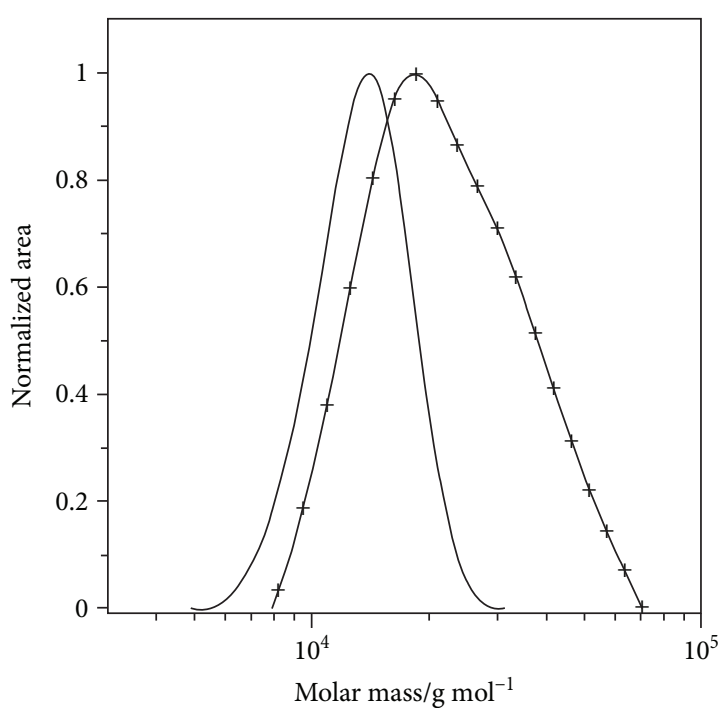

FIGURE 3: SEC chromatogram of PDMS homopolymer and $\mathrm{P}$ (DMS- $b-\varepsilon$-CL) SCL4 block copolymer. Symbols: (-) PDMS and (+) SCL4.

PDMS-OH macroinitiator. It is inferred that, with an additional purification step of commercial $\varepsilon$-CL monomer (for example, a previous treatment with calcium hydride), the presence of water or hydroxyl impurities will be diminished or suppressed. HEMACL\# copolymers exhibited $M_{\mathrm{n}}$ values between $32,300 \mathrm{~g} \mathrm{~mol}^{-1}$ and $46,000 \mathrm{~g} \mathrm{~mol}^{-1}$, and $M_{\mathrm{w}} / M_{\mathrm{n}}$ lower than 1.2, indicating a good control of the process over the chemical characteristics of the resulting macromolecules (Table 1). This fact proves the efficiency of the one-pot procedure to produce macromolecular architectures by employing RAFT and ROP simultaneously. As an additional fact, the expected molar masses can be achieved at reasonable reaction times (at least, $1 \mathrm{~h}$ ) which is another feature that supports the efficiency of the proposed procedure. At this point, it is worth mentioning that HEMACL\# copolymers deserve an additional purification process. In such a sense, Figure 4 displays SEC chromatograms from the crude reaction product and the resulting HEMACL3 copolymer after the purification process. As it can be seen, the crude reaction product contains residual PCL homopolymer (from BSTSE as well as from HEMA monomer) that disappears by successive precipitation employing controlled temperature and nonsolvent (methanol) fractionation.

DSC measurements were performed in order to evaluate thermal transitions from linear and "graft-like" PCL-based copolymers when compared to linear PCL (at this point, it should be mentioned that the temperature range under study was selected by taking into account the $T_{\mathrm{m}}$ of the PCL block from HEMACL\# copolymers, which is lower than that corresponding to the PCL homopolymer employed for comparison purposes; for more details, please refer to Table 1). For SCL\# samples, three transitions are detected (Figures 5(a) and 5(b)): $T_{\mathrm{g}}$ from the PCL block $\left(T_{\mathrm{gPCL}} \sim-60^{\circ} \mathrm{C}\right), T_{\mathrm{m}}$ of the semicrystalline PDMS block $\left(T_{\mathrm{mPDMS}} \sim-45^{\circ} \mathrm{C}\right)$, and $T_{\mathrm{m}}$ of the PCL block $\left(T_{\mathrm{mPCL}} \sim 54^{\circ} \mathrm{C}\right)$. On the other hand, for linear PCL, $T_{\mathrm{mPCL}}$ is detected at $\sim 56^{\circ} \mathrm{C}$ (Figure $5(\mathrm{c})$ ), whereas for HEMACL\# copolymers, $T_{\text {mPCL }}$ from PCL grafts is observed at $\sim 40^{\circ} \mathrm{C}$ (Figure $5(\mathrm{~d})$ ). This reduction on the $T_{\mathrm{m}}$ of PCL could be explained by taking into account the presence of random grafted PCL chains along the PHEMA backbone $[27,28,54]$. It is reasonable to suppose that longer reaction times allow higher density of PCL grafts (HEMACL3), whereas lower PCL grafts are expected for shorter reaction times (HEMACL2). This is quite reasonable since BSTSE acts as both a RAFT and ROP initiator. For short reaction times, few PCL grafts are attached from the PHEMA block because reaction time is not enough to achieve a good RAFT conversion. On the contrary, at higher reaction times, the probability to have randomly distributed grafts along PHEMA blocks increases. In addition, for these copolymers, a final thermal event around $68^{\circ} \mathrm{C}$ (associated to $T_{\text {gPHEMA }}$ from PHEMA block) was also observed (Figure 5(d) and Table 1) [55].

Isothermal crystallization curves of linear PCL, SCL\#, and HEMACL\# copolymers are displayed in Figure 6, in which the evolution of endothermic heat flow was recorded as a function of time. In Figure 6(a), the isothermal crystallization curves of linear PCL are plotted at different $T_{c}$ values. As it can be seen, crystallization time is increased at higher $T_{c}$ values, indicating that nucleation is the limiting factor for crystallization in this temperature range [56]. A similar behavior was observed for SCL\# and HEMACL\# copolymers. As examples, Figure 6(b) shows the crystallization evolution of linear PCL, SCL2, and HEMACL2 at $T_{\mathrm{c}}=20^{\circ} \mathrm{C}$. It is important to note that the completed crystallization processes of SCL2 and HEMACL2 copolymers occur at higher times when compared to linear PCL. For SCL2, this rise can be associated with the noncrystallizable PDMS block (Table 2). In this sense, Lovinger et al. [57] reported that the PDMS block avoids the regular crystallization of PCL chains because of the higher mobility of the viscoelastic, amorphous PDMS block throughout the crystallization process. On the other hand, HEMACL\# copolymers show a wider difference, because the presence of random, grafted branches hinders the formation of PCL crystallites by increasing crystallization time values (Table 2) [12].

As it is reported in the literature $[35,58]$, isothermal crystallization kinetics can be better visualized by considering the relative degree of crystalline conversion as a function of time at different crystallization temperatures (Figure 7). Then, relative crystallinity, related to the crystalline volume $\left(V_{c}\right)$, vs. different crystallization times $(t)$, can be calculated from $[1,32,35,49]$

$$
V_{\mathrm{c}}=\frac{\Delta H_{t}}{\Delta H_{\infty}}=\frac{\int_{t_{0}}^{t}\left(\mathrm{~d} H_{c} / \mathrm{d} t\right) d t}{\int_{t_{0}}^{t_{\infty}}\left(\mathrm{d} H_{c} / \mathrm{d} t\right) d t},
$$

where $\Delta H_{t}$ and $\Delta H_{\infty}$ are the heat generated at time $t$ and at long time periods, respectively, and $\mathrm{dHc} / \mathrm{d} t$ is heat evolution rate. $V_{\mathrm{c}}$ is obtained from the area of the exothermic peak on isothermal crystallization and is plotted vs. time (Figure 7). The slope of the graphs appears as an S-like shape. The Slike shape in the graphs with higher slopes reveals higher 
TABLE 1: Chemical and thermal characterization of synthesized linear PCL and PDMS-OH homopolymers, and PCL-based copolymers.

\begin{tabular}{|c|c|c|c|c|c|c|c|c|c|}
\hline Polymer & $M_{\mathrm{n}}^{(\mathrm{a})} / \mathrm{g} \mathrm{mol}^{-1}$ & $M_{\mathrm{w}} / M_{\mathrm{n}}^{(\mathrm{a})}$ & $w_{\mathrm{PCL}}^{(\mathrm{b})}$ & $T_{\mathrm{gPCL}}{ }^{(\mathrm{c})} /{ }^{\circ} \mathrm{C}$ & $T_{\text {gPHEMA }}{ }^{(\mathrm{c})} /{ }^{\circ} \mathrm{C}$ & $T_{\text {mPDMS }}^{(\mathrm{c})} /^{\circ} \mathrm{C}$ & $T_{\mathrm{mPCL}}{ }^{(\mathrm{c})} /^{\circ} \mathrm{C}$ & $T_{0.05}{ }^{(\mathrm{d})} /{ }^{\circ} \mathrm{C}$ & $E_{\mathrm{ad}}{ }^{(\mathrm{d})} / \mathrm{kJ} \mathrm{mol}^{-1}$ \\
\hline PCL & 11,000 & 1.14 & 1 & -66.0 & - & - & 55.9 & 341.5 & 217.6 \\
\hline PDMS-OH & 13,000 & 1.07 & - & - & - & -44.9 & - & 340.0 & 102.1 \\
\hline SCL1 & 20,000 & 1.36 & 0.35 & -59.1 & - & -42.4 & 50.4 & 205.1 & 147.4 \\
\hline SCL2 & 21,300 & 1.33 & 0.39 & -59.6 & - & -43.4 & 51.1 & 247.3 & 142.3 \\
\hline SCL3 & 25,000 & 1.45 & 0.48 & -59.9 & - & -43.9 & 47.3 & 241.9 & 152.6 \\
\hline SCL4 & 65,000 & 1.54 & 0.80 & -62.1 & - & -45.2 & 54.8 & 195.7 & 172.7 \\
\hline HEMACL1 & 32,300 & 1.19 & 0.89 & -63.3 & 68.7 & - & 41.1 & 231.6 & 132.5 \\
\hline HEMACL2 & 38,600 & 1.13 & 0.93 & -63.1 & 67.9 & - & 38.2 & 227.4 & 134.7 \\
\hline HEMACL3 & 46,000 & 1.11 & 0.97 & -63.4 & 68.2 & - & 42.9 & 225.3 & 131.4 \\
\hline
\end{tabular}

${ }^{(a)}$ Number average molar mass $\left(M_{\mathrm{n}}\right)$ and polydispersity $\left(M_{\mathrm{w}} / M_{\mathrm{n}}\right)$ determined by SEC and ${ }^{1} \mathrm{H}-\mathrm{NMR}$; ${ }^{(\mathrm{b})}$ weight fraction of PCL in the block copolymer determined by ${ }^{1} \mathrm{H}-\mathrm{NMR} ;{ }^{(\mathrm{c})}$ glass-transition temperature $\left(T_{\mathrm{g}}\right)$ and melting temperature $\left(T_{\mathrm{m}}\right)$ determined by DSC; ${ }^{\text {(d) }} 5 \%$ thermal degradation temperature $\left(T_{0.05}\right)$ and activation energy for degradation $\left(E_{\text {ad }}\right)$ determined by MTGA.

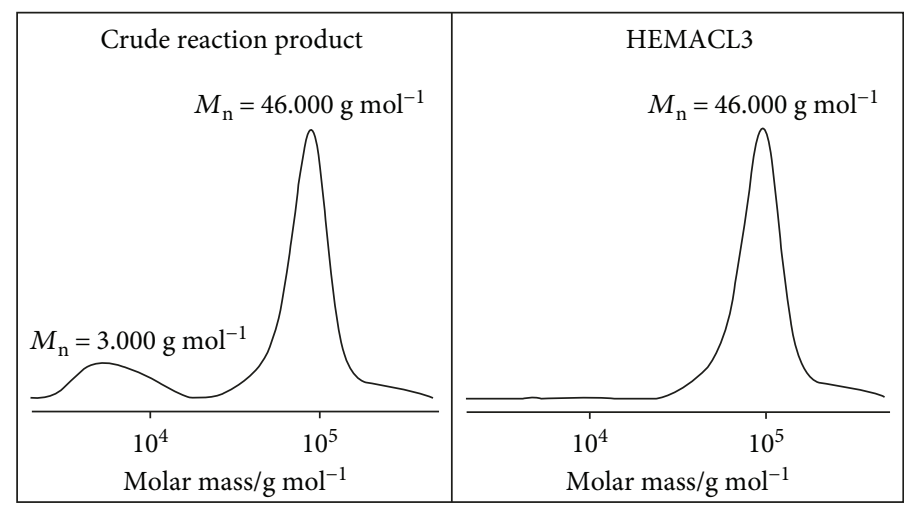

FIGURE 4: SEC chromatograms from the crude reaction product and the resulting HEMACL3 copolymer after the purification process.

rates for relative crystallization vs. time, indicating a faster crystallization rate at lower $T_{c}$ values (Figures $7(\mathrm{a})-7(\mathrm{c})$ ). As examples, at a given $T_{c}$ value, SCL\# and HEMACL\# copolymers crystallize at a lower rate when compared to linear PCL as it can be deduced by exploring time values at a given relative crystallinity $\%$ (Figure $7(\mathrm{~d})$ ).

The above-described results allow employing Avrami's theory to obtain kinetics parameters of interest such as the half-life time for crystallization $\left(t_{1 / 2}\right)$, the bulk crystallization constant $(k)$, and Avrami's exponent $(n)$, by following $[2,15,49]$

$$
V_{\mathrm{c}}=1-\exp \left(-k t^{n}\right)
$$

This equation can be rewritten in a double logarithmic form as follows:

$$
\log \left[-\ln \left(1-V_{c}\right)\right]=\log k+n \log \left(t-t_{0}\right)
$$

where $V_{c}$ is related to the relative crystallinity from polymers at different temperatures or times, and $t-t_{0}$ is the crystallization period involved in the process. The induction time (which includes the stabilization time) has been named $t_{0}$, and it was calculated by drawing a horizontal line from a point after the finishing crystallization process to a point at the beginning of the crystallization curve, by following the methodology reported by Lorenzo et al. [34]. In addition, $n$ represents crystallization types regarding dimensions (one-, two-, or three-dimensional) and $k$ is a growth rate constant that accounts for both nucleation and growth rate parameters.

Plots of $\log \left[-\ln \left(1-V_{c}\right)\right]$ vs. $\log \left(t-t_{0}\right)$ for each crystallization temperature $\left(T_{\mathrm{c}}\right)((3))$ are shown in Figure 8 . Avrami's exponent $n$ and crystallization rate $k$ are obtained from the slope and intercept of the curves, respectively. From these curves, $t_{1 / 2}$ is defined as the time required for developing $50 \%$ of final crystallinity. Usually, lower $t_{1 / 2}$ values are expected at higher crystallization rates (Table 2).

As example, for HEMACL3, all lines were almost straight and parallel to each other, shifting to a higher time when the crystallization temperature increases (Figure 8(a)). In addition, at $T_{\mathrm{c}}=20^{\circ} \mathrm{C}$, the corrected Avrami's fit was evidenced for both linear PCL and copolymers (Figure 8(b)). Moreover, for SCL\# copolymers, $n$ values were similar to those obtained for linear PCL, with calculated values between 2.4 and 3.4 (see Table 2). It is important to highlight that these values refer to a three-dimensional heterogeneous nucleation and they are in good agreement with values already reported $[33,36,56]$. On the other hand, HEMACL\# copolymers show values of $n$ exponent from 1.8 to 2.6, 


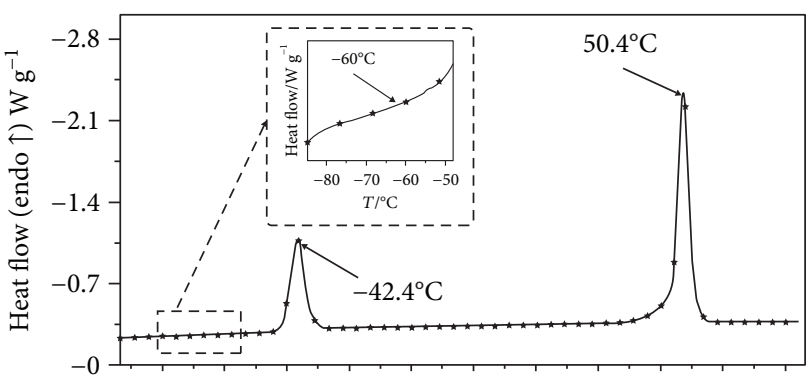

(a)

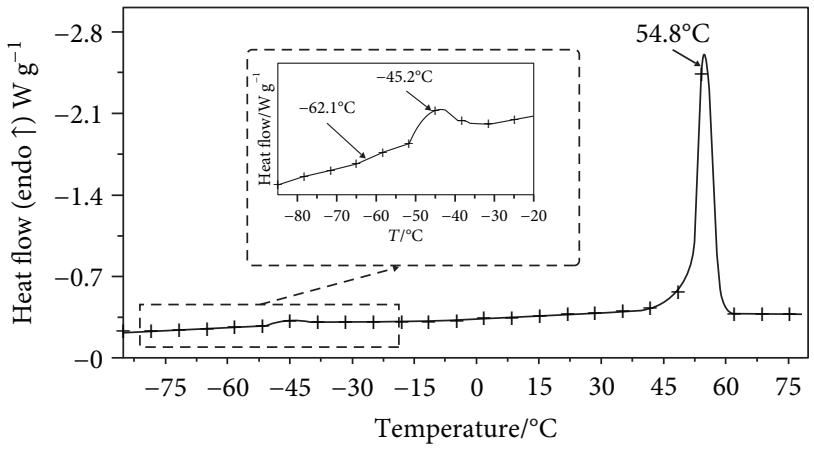

(c)

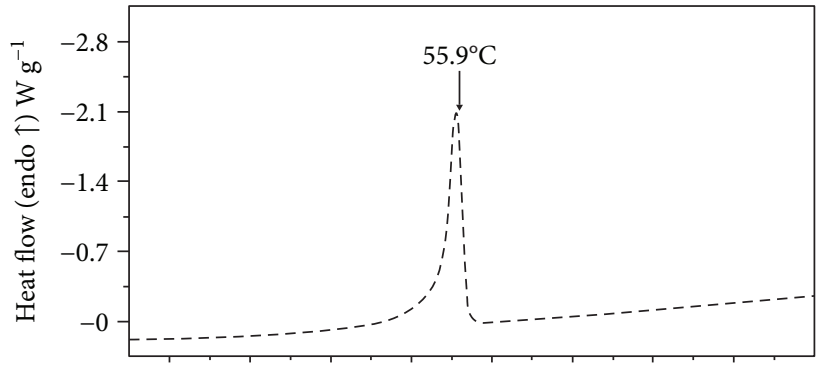

(b)

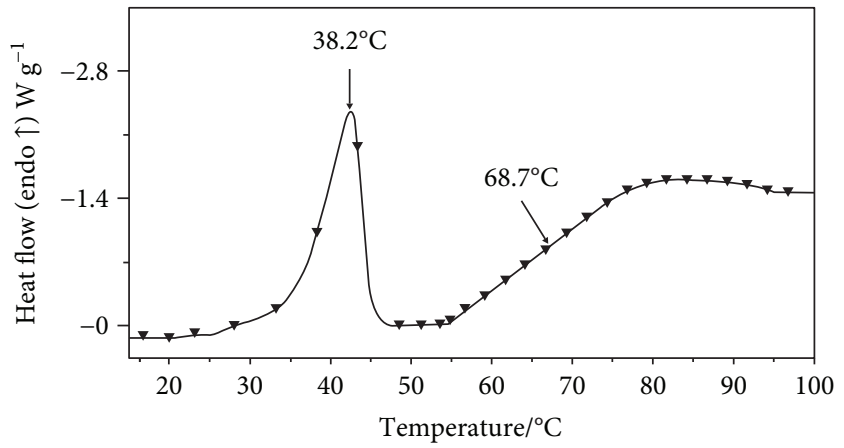

(d)

FIguRe 5: DSC curves of (a) P (DMS- $b$ - $\varepsilon$-CL) SCL1, (b) P (DMS- $b$ - $\varepsilon$-CL) SCL4, (c) linear PCL homopolymer, and (d) P (HEMA-co-(HEMA$g-\varepsilon-C L)-b-\varepsilon-C L)$ HEMACL3 copolymers.

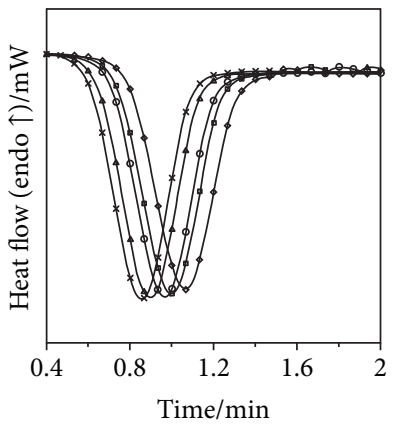

(a)

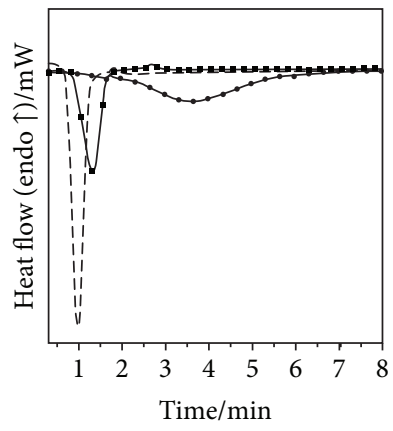

(b)
Figure 6: Crystallization endothermic curves for (a) linear poly $(\varepsilon$ caprolactone) homopolymer (PCL), symbols: $(\times) T_{c}=16^{\circ} \mathrm{C},(\Delta)$ $T_{\mathrm{c}}=18^{\circ} \mathrm{C}$, (O) $T_{\mathrm{c}}=20^{\circ} \mathrm{C},(\square) T_{\mathrm{c}}=22^{\circ} \mathrm{C}$ and $(\diamond) T_{c}=24^{\circ} \mathrm{C}$; and $(\mathrm{b})$ linear PCL, SCL2 and HEMACL2 copolymers, crystallized at

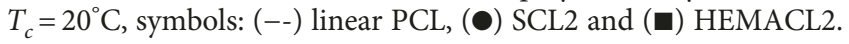

revealing that these "comb-like" copolymers adopt a twodimensional crystallization growth with heterogeneous nucleation $[32,35,36,59]$. The effect is strongly dependent on the number of branches, as it can be easily deduced by comparing the resulting curves for HEMACL1 and HEMACL3. It is reasonable to suppose that the presence of branches imposes dimensional restrictions over the resulting crystallites, by changing from three (linear) to two (comb-like) dimensions.

In Avrami's equation, $k$ values are related with nucleation rate and growth processes. For SCL\# and HEMACL\# copolymers, a decrease in this parameter with an increase in $T_{\mathrm{c}}$ was observed. The presence of the PDMS block in
SCL\# or grafted, random PCL branches in HEMACL\# lead to a reduction in $k$ values in all the studied samples (see Table 2). This reduction could be explained by taking into account the spatial configuration of PDMS block or grafted PCL branches. During the folding and growth processes of crystals, the viscoelastic silicon block as well as the random PCL branches hinder the normal crystallization event, leading to lower $k$ values. The effect can be easily appreciated in Figure 9, in which the evolution of $t_{1 / 2}$ at each $T_{c}$ value is shown.

For SCL\# copolymers, $t_{1 / 2}$ values exhibited an increase of 1.6 times when compared to linear PCL (Figure 9(a)). On the other hand, for HEMACL\# copolymers, a difference in $t_{1 / 2}$ values appears at crystallization temperatures closer to $T_{\text {mPCL }}$. In this sense, HEMACL2 and HEMACL3 show $t_{1 / 2}$ values of 18 and 42 times higher when compared to linear PCL, respectively (as it can be appreciated for temperatures between 20 and $24^{\circ} \mathrm{C}$, Figure 9(b)). From Figure 9, it is clear that "flat" curves can be obtained for SCL\# copolymers whereas marked changes were observed for HEMACL\# copolymers when compared to linear PCL. The "comb-like" structure of these copolymers noticeably affects the crystallization behavior of the semicrystalline PCL block since random grafts require more time for crystallization.

Finally, activation energy for isothermal crystallization was evaluated by using the Arrhenius equation $[35,56,59]$ :

$$
\left(\frac{1}{n}\right) \ln K=\ln K_{0}-\frac{\Delta E_{\mathrm{a}}}{R T_{\mathrm{c}}},
$$


TABLE 2: Values of $t_{1 / 2}(\mathrm{~min}), n, k\left(\mathrm{~min}^{-1}\right)$, and $\Delta E_{\mathrm{a}}$ at different crystallization temperatures $\left(T_{\mathrm{c}}\right)$ for linear PCL, SCL\#, and HEMACL\# copolymers.

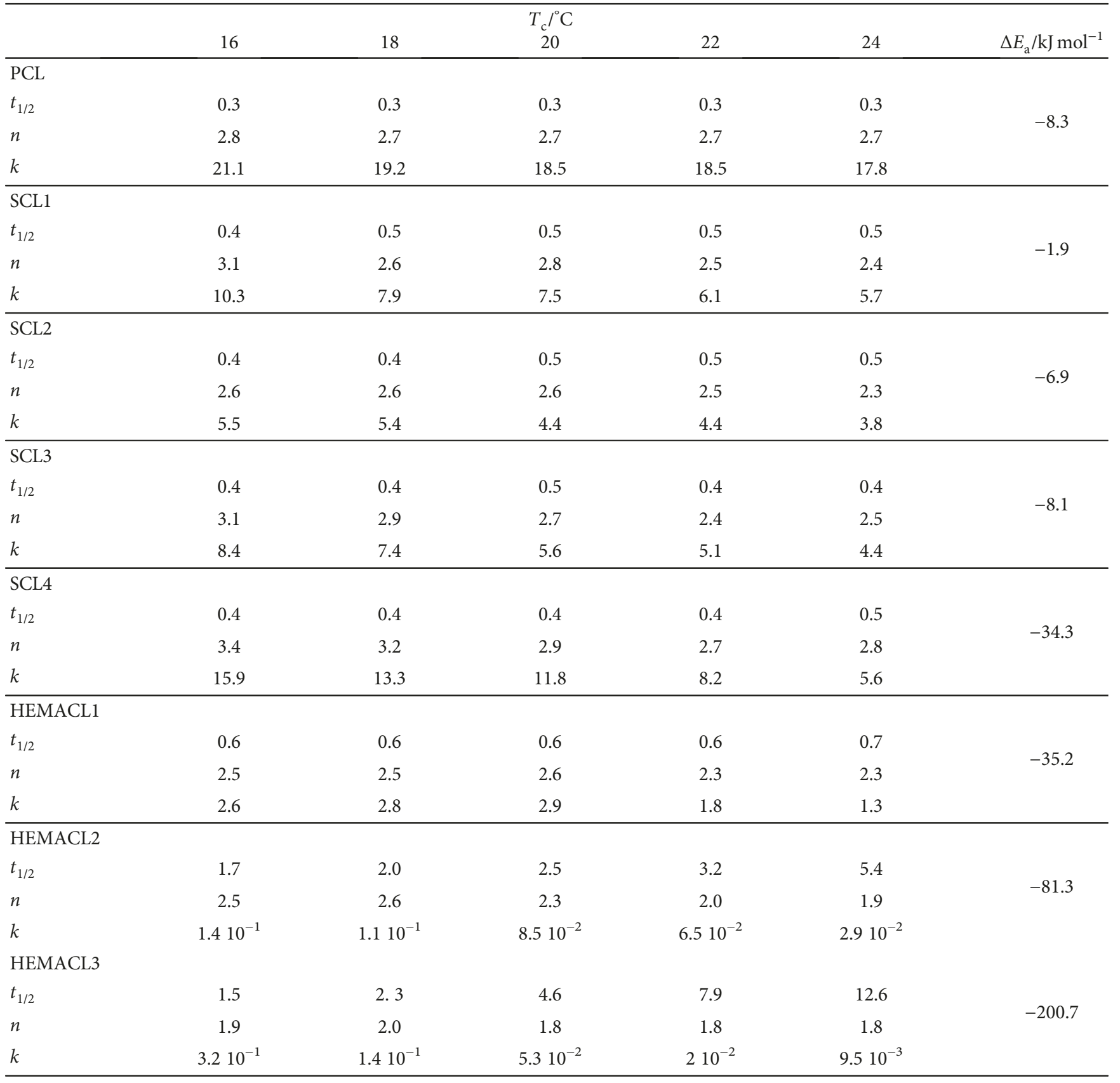

where $K_{0}$ is a temperature-independent preexponential factor, $\Delta E_{\mathrm{a}}$ is the total activation energy, and $R$ is the universal gas constant.

Arrhenius plots of $n^{-1} \ln K$ versus $T_{c}^{-1}$ for linear PCL, SCL\#, and HEMACL\# copolymers were linear, and $\Delta E_{\mathrm{a}}$ was determined from the slope of the curves (Figure 10). Values are summarized in Table 2. For all samples, the calculated $\Delta E_{\mathrm{a}}$ values were negatives. In this sense, Dhanvijay et al. [36] refer this behavior to the released energy during melt to crystalline state transformation. By comparing linear PCL with SCL\# and HEMACL\# copolymers, the $\triangle E_{\mathrm{a}}$ values of HEMACL\# copolymers are the highest. $\Delta E_{\mathrm{a}}$ values are strongly dependent on the comonomer presence, whose chemical nature and macromolecular structure affect PCL chains. Therefore, collisions and entanglements of PDMS and PCL blocks are important when the amount of PCL increases in SCL\# copolymers. On the other hand, the random grafted PCL chains hinder movement and rearrangement of the semicrystalline PCL block by reducing their crystallization ability. These results 


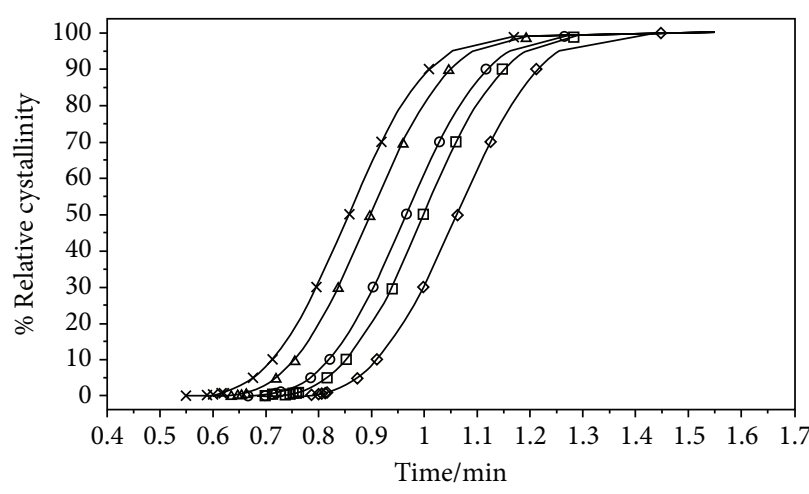

(a)

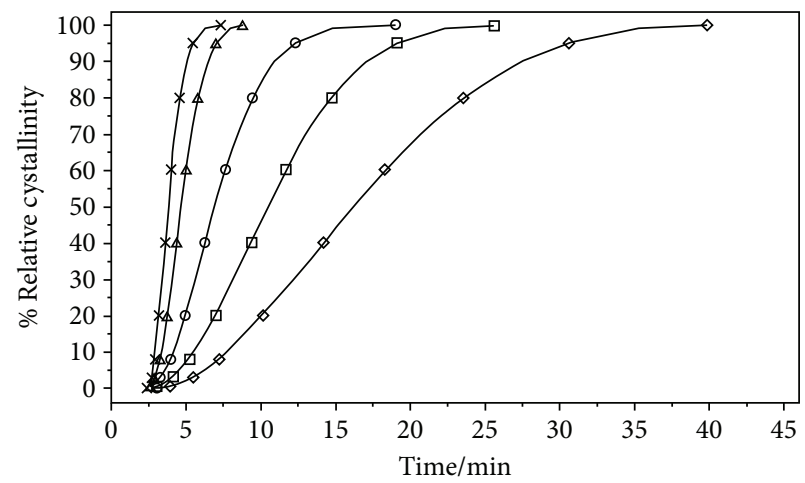

(c)

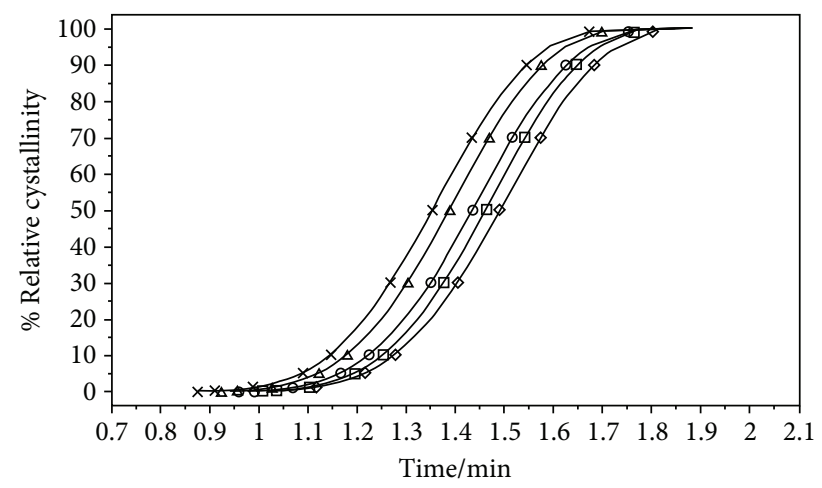

(b)

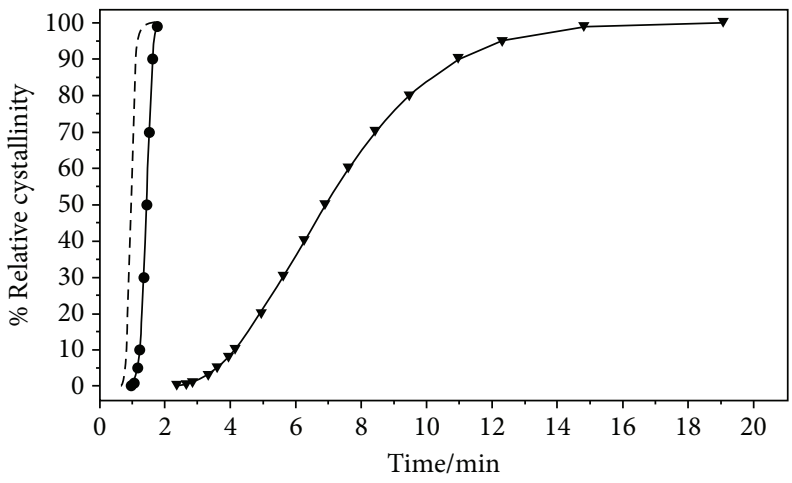

(d)

FIgure 7: Relative Crystallinity (\%) as a function of time ( $\mathrm{min}$ ) for: (a) linear poly ( $\varepsilon$-caprolactone) PCL, (b) SCL2, (c) HEMACL3. Symbols: $(\times) T_{c}=16^{\circ} \mathrm{C},(\Delta) T_{c}=18^{\circ} \mathrm{C},(\bigcirc) T_{c}=20^{\circ} \mathrm{C},(\square) T_{c}=22^{\circ} \mathrm{C}$, and $(\diamond) T_{c}=24^{\circ} \mathrm{C}$. (d) Linear PCL, SCL2, and HEMACL3 copolymers, crystallized at $T_{\mathrm{c}}=20^{\circ} \mathrm{C}$, symbols: $(-)$ linear PCL, $(\bullet)$ SCL2, and $(\boldsymbol{\nabla})$ HEMACL3.

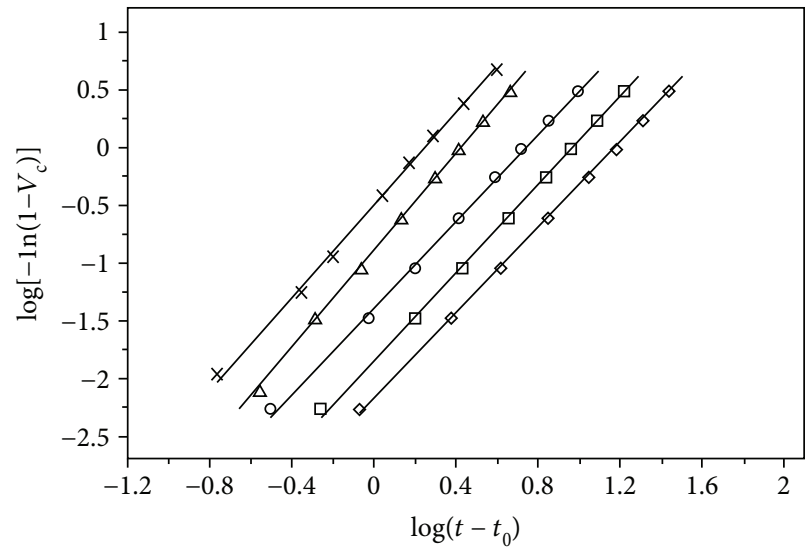

(a)

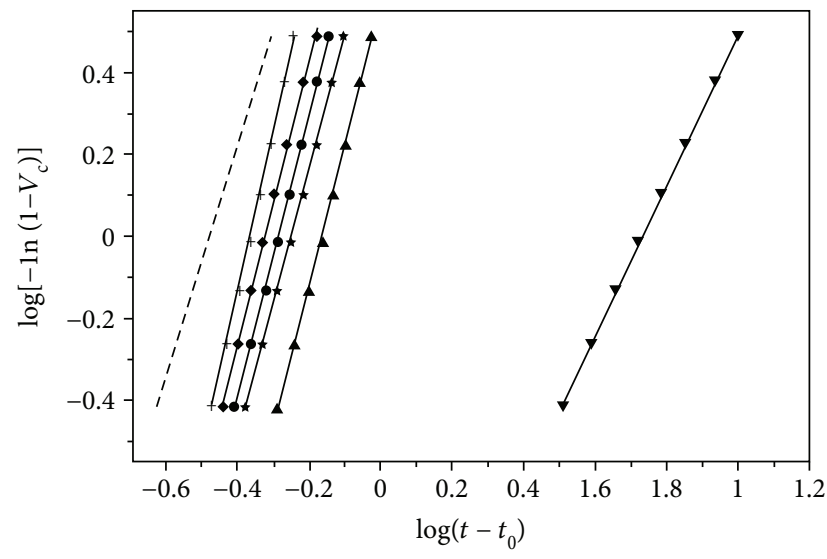

(b)

FIgURE 8: Experimental data obtained from the isothermal crystallization of (a) HEMACL3 at different crystallization temperature ( $\left.T_{c}\right)$, symbols: $(\times) T_{\mathrm{c}}=16^{\circ} \mathrm{C},(\Delta) T_{\mathrm{c}}=18^{\circ} \mathrm{C},(\mathrm{O}) T_{\mathrm{c}}=20^{\circ} \mathrm{C},(\square) T_{\mathrm{c}}=22^{\circ} \mathrm{C}$, and $(\diamond) T_{\mathrm{c}}=24^{\circ} \mathrm{C}$ and (b) linear poly $(\varepsilon$-caprolactone) homopolymer

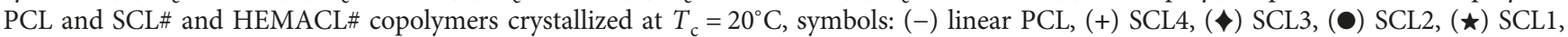
(ム) HEMACL1, and ( $\boldsymbol{\nabla})$ HEMACL3.

are in accordance with the behavior reported by Cai et al. [59] when isothermal crystallization of PCL composites was analyzed.

According to the thermogravimetric analysis, weight loss events associated to linear and "comb-like" copolymers as function of temperature were registered (Figure 11). In addition, values of temperature at $5 \%$ of thermal degradation $\left(T_{0.05}\right)$ were included in Table 1 for each sample. It is important to note that $T_{0.05}$ values denote the beginning of the thermal degradation process, which is a characteristic 


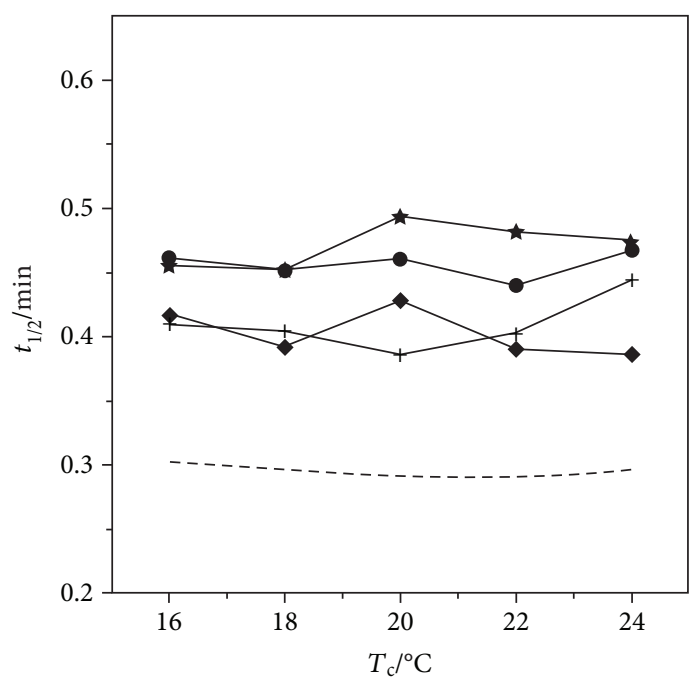

(a)

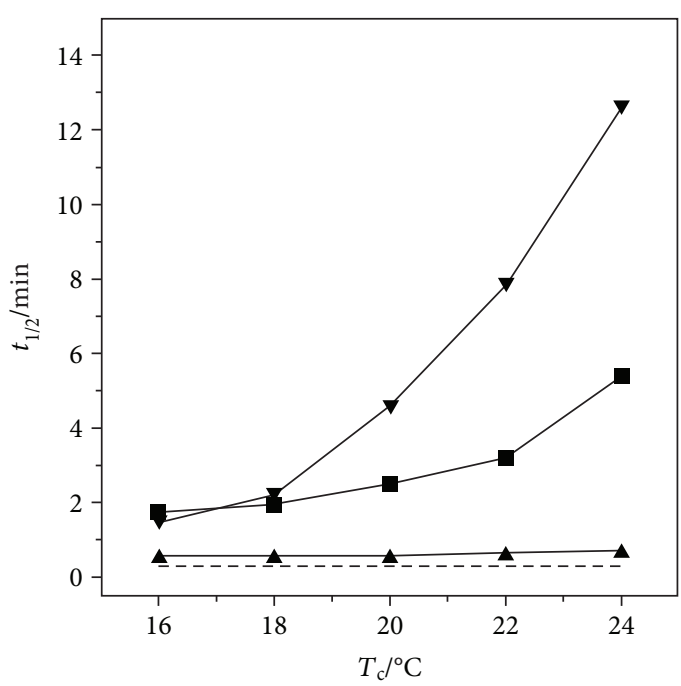

(b)

FIGURE 9: Dependence of $t_{1 / 2}$ with the isothermal crystallization temperature $\left(T_{\mathrm{c}}\right)$ for (a) linear PCL and SCL\# copolymers, symbols: (-)

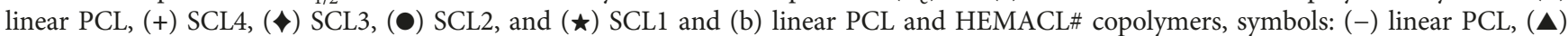
HEMACL1, (ם) HEMACL2, and $(\boldsymbol{\nabla})$ HEMACL3.

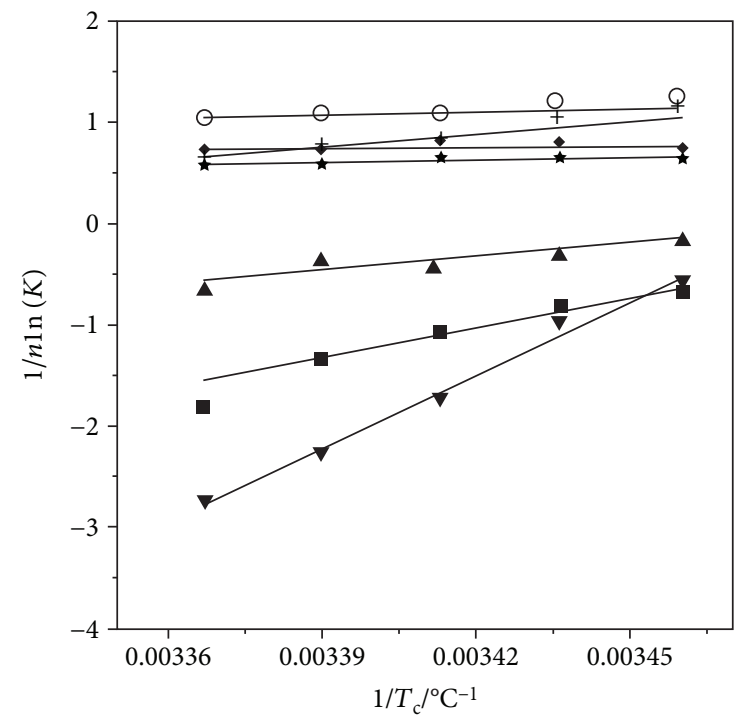

Figure 10: Arrhenius plots $1 / n \ln (K)$ vs. $1 / T_{c}$ for linear PCL homopolymer and SCL\# and HEMACL\# copolymers. Symbols:

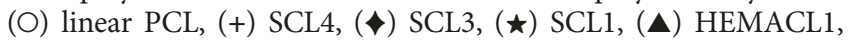
(घ) HEMACL2, and ( $\boldsymbol{\nabla})$ HEMACL3.

value for each polymer that depends on many macromolecular features.

Figure 11 shows MTGA curves corresponding to linear PCL homopolymer and SCL4 and HEMACL3 copolymers, respectively. As it can be seen, linear PCL presents a typical weight loss step which is associated to PCL decomposition at $341^{\circ} \mathrm{C}[59,60]$. By analyzing the first derivative curve from the MTGA thermogram (not shown), for the SCL4 copolymer three thermal degradation events were detected. These events were observed at $193^{\circ} \mathrm{C}$ (rupture of polyester chains via ester pyrolysis reaction producing $\mathrm{H}_{2} \mathrm{O}, \mathrm{CO}_{2}$, and

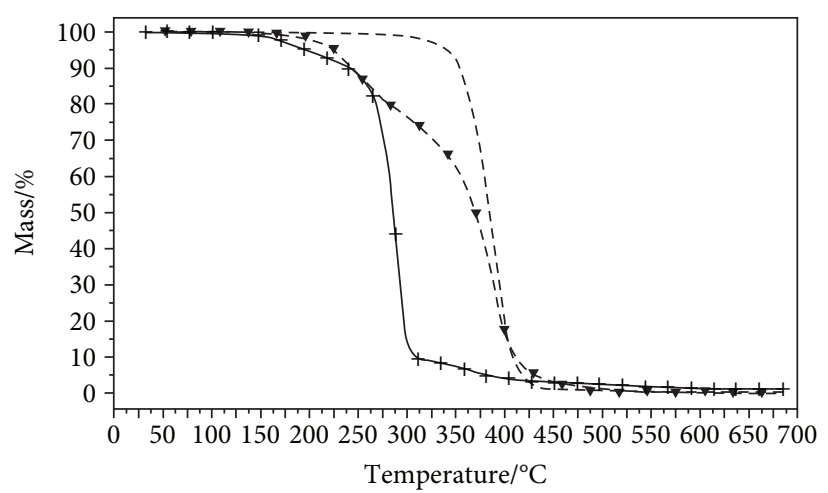

FIgURE 11: MTGA curves of linear PCL homopolymer and SCL\# and HEMACL\# copolymers. Symbols: (-) linear PCL, (+) SCL4, and $(\boldsymbol{\nabla})$ HEMACL3.

5-hexenoic acid); at $289^{\circ} \mathrm{C}$ (PCL block decomposition), and at $366^{\circ} \mathrm{C}$ (PDMS block degradation) [32,61]. On the other hand, HEMACL\# copolymers showed the thermal decomposition associated to PHEMA and PCL homopolymers already reported $[28,62]$.

All the studied materials exhibited a reduction in the maximum degradation temperature when compared to linear PCL. In this sense, thermal degradation was faster for SCL\# than HEMACL\# copolymers, denoting that the PCL block is less thermally stable in the $150-450^{\circ} \mathrm{C}$ range. A plausible explanation might be due to the hydroxyl-end group $(-\mathrm{OH})$. For block copolymers, it is reasonable to assume one $-\mathrm{OH}$ group per molecule (PCL block), whereas the amount increases for comb-like copolymers (-OH groups from PCL grafts and PCL block). Since the chemical nature of end-groups strongly influences the thermal behavior of PCL [63], the differences observed can be reasonable explained. The calculated activation energy values $\left(E_{\mathrm{ad}}\right)$ for 
SCL\# and HEMACL\# copolymers were lower than the corresponding value for linear PCL (Table 1). These results agree well with previous works regarding the thermal degradation of PCL-based copolymers reported by Ninago et al. [32].

\section{Conclusions}

Linear and block copolymers based on $\varepsilon$-CL were successfully synthesized through a combination of anionic, RAFT, and ROP methods. Samples showed $M_{\mathrm{w}} / M_{\mathrm{n}}<1.54$, which reveal a good control over macromolecular architectures. Isothermal DSC experiments (combined with Avrami's theory) were performed in order to obtain kinetics parameters regarding crystallization behavior. For the temperature range studied (from $T_{\mathrm{c}}=16^{\circ} \mathrm{C}$ to $T_{\mathrm{c}}=24^{\circ} \mathrm{C}$ ), $k$ values were reduced whereas $t_{1 / 2}$ values were increased when compared to the linear PCL homopolymer. The effect was more notorious for HEMACL\# copolymers, in which branch density might affect crystallization processes due to less chain mobility and spatial hindrance. Regarding thermal stabilities, the presence of $-\mathrm{OH}$ groups from PCL branches reduces the energy barrier of the thermal degradation process for the corresponding HEMACL\# copolymers.

\section{Data Availability}

The data used to support the findings of this study are available from the corresponding author upon request.

\section{Conflicts of Interest}

The authors declare that there is no conflict of interest regarding the publication of this paper.

\section{Acknowledgments}

We express our gratitude to the Consejo Nacional de Investigaciones Científicas y Técnicas (CONICET, Argentina, grant PIP 0428), the Fondo para la Investigación Científica y Tecnológica (FONCyT, Argentina, grant PICT-2016-0181) and the Universidad Nacional de Cuyo (UNCuyo, Argentina) for their financial support.

\section{References}

[1] N. A. Agudelo and L. D. Perez, "Synthesis and characterization of polydimethylsiloxane end-modified polystyrene from poly (styrene - co -vinyltriethoxysilane) copolymers," Materials Research, vol. 19, no. 2, pp. 459-465, 2016.

[2] M. B. Runge, S. Dutta, and N. B. Bowden, "Synthesis of comb block copolymers by ROMP, ATRP, and ROP and their assembly in the solid state," Macromolecules, vol. 39, no. 2, pp. 498-508, 2006.

[3] M. D. Ninago, V. Hanazumi, M. G. Passaretti, D. A. Vega, A. E. Ciolino, and M. A. Villar, "Enhancement of mechanical and optical performance of commercial polystyrenes by blending with siloxane-based copolymers," Journal of Applied Polymer Science, vol. 134, no. 30, 2017.
[4] N. Hadjichristidis, S. Pispas, and G. Floudas, Block Copolymers: Synthetic Strategies, Physical Properties, and Applications, John Wiley \& Sons, Inc., Hoboken, NJ, USA, 2003.

[5] S. V. Murphy and A. Atala, "3D bioprinting of tissues and organs," Nature Biotechnology, vol. 32, no. 8, pp. 773-785, 2014.

[6] J. Y. Lee, J. An, and C. K. Chua, "Fundamentals and applications of 3D printing for novel materials," Applied Materials Today, vol. 7, pp. 120-133, 2017.

[7] X. Qu, P. Xia, J. He, and D. Li, "Microscale electrohydrodynamic printing of biomimetic PCL/nHA composite scaffolds for bone tissue engineering," Materials Letters, vol. 185, pp. 554-557, 2016.

[8] Y. He, C. J. Tuck, E. Prina et al., "A new photocrosslinkable polycaprolactone-based ink for three-dimensional inkjet printing," Journal of Biomedical Materials Research Part B: Applied Biomaterials, vol. 105, no. 6, pp. 1645-1657, 2017.

[9] H. N. Chia and B. M. Wu, "Recent advances in 3D printing of biomaterials," Journal of Biological Engineering, vol. 9, no. 1, p. 4, 2015.

[10] S. Agarwal, A. Greiner, and J. H. Wendorff, "Functional materials by electrospinning of polymers," Progress in Polymer Science, vol. 38, no. 6, pp. 963-991, 2013.

[11] T. J. Sill and H. A. von Recum, "Electrospinning: applications in drug delivery and tissue engineering," Biomaterials, vol. 29, no. 13, pp. 1989-2006, 2008.

[12] J. L. Wietor, D. J. M. Van Beek, G. W. Peters, E. Mendes, and R. P. Sijbesma, "Effects of branching and crystallization on rheology of polycaprolactone supramolecular polymers with ureidopyrimidinone end groups," Macromolecules, vol. 44, no. 5, pp. 1211-1219, 2011.

[13] M. Yazdimamaghani, M. Razavi, D. Vashaee, V. R. Pothineni, J. Rajadas, and L. Tayebi, "Significant degradability enhancement in multilayer coating of polycaprolactone-bioactive glass/gelatin-bioactive glass on magnesium scaffold for tissue engineering applications," Applied Surface Science, vol. 338, pp. 137-145, 2015.

[14] J. Z. Liang, L. Zhou, C. Y. Tang, and C. P. Tsui, “Crystallization properties of polycaprolactone composites filled with nanometer calcium carbonate," Journal of Applied Polymer Science, vol. 128, no. 5, pp. 2940-2944, 2013.

[15] E. C. Chen and T. M. Wu, "Isothermal crystallization kinetics and thermal behavior of poly ( $\varepsilon$-caprolactone)/multi-walled carbon nanotube composites," Polymer Degradation and Stability, vol. 92, no. 6, pp. 1009-1015, 2007.

[16] C. Varan, H. Wickström, N. Sandler, Y. Aktaş, and E. Bilensoy, "Inkjet printing of antiviral PCL nanoparticles and anticancer cyclodextrin inclusion complexes on bioadhesive film for cervical administration," International Journal of Pharmaceutics, vol. 531, no. 2, pp. 701-713, 2017.

[17] T. V. Chirila, I. J. Constable, G. J. Crawford et al., "Poly (2hydroxyethyl methacrylate) sponges as implant materials: in vivo and in vitro evaluation of cellular invasion," Biomaterials, vol. 14, no. 1, pp. 26-38, 1993.

[18] N. A. Peppas, H. J. Moynihan, and L. M. Lucht, "The structure of highly crosslinked poly (2-hydroxyethyl methacrylate) hydrogels," Journal of Biomedical Materials Research Part A, vol. 19, no. 4, pp. 397-411, 1985.

[19] J. L. Zhu, X. Z. Zhang, H. Cheng, Y. Y. Li, S. X. Cheng, and R. X. Zhuo, "Synthesis and characterization of well-defined, amphiphilic poly (N-isopropylacrylamide)-b-[2-hydroxyethyl 
methacrylate-poly ( $\varepsilon$-caprolactone)]n graft copolymers by RAFT polymerization and macromonomer method," Journal of Polymer Science Part A: Polymer Chemistry, vol. 45, no. 22, pp. 5354-5364, 2007.

[20] A. G. O. de Freitas, S. G. Trindade, P. I. R. Muraro et al., "Controlled one-pot synthesis of polystyrene-blockpolycaprolactone copolymers by simultaneous RAFT and ROP," Macromolecular Chemistry and Physics, vol. 214, no. 20, pp. 2336-2344, 2013.

[21] M. Le Hellaye, C. Lefay, T. P. Davis, M. H. Stenzel, and C. Barner-Kowollik, "Simultaneous reversible addition fragmentation chain transfer and ring-opening polymerization," Journal of Polymer Science Part A: Polymer Chemistry, vol. 46, no. 9, pp. 3058-3067, 2008.

[22] X. Qin, Y. Li, F. Zhou, L. Ren, Y. Zhao, and X. Yuan, "Polydimethylsiloxane-polymethacrylate block copolymers tethering quaternary ammonium salt groups for antimicrobial coating," Applied Surface Science, vol. 328, pp. 183-192, 2015.

[23] G. Moad, Y. K. Chong, A. Postma, E. Rizzardo, and S. H. Thang, "Advances in RAFT polymerization: the synthesis of polymers with defined end-groups," Polymer, vol. 46, no. 19, pp. 8458-8468, 2005.

[24] F. Azemar, F. Faÿ, K. Réhel, and I. Linossier, "Control of hydration and degradation properties of triblock copolymers polycaprolactone- $b$-polydimethylsiloxane- $b$-polycaprolactone," Journal of Applied Polymer Science, vol. 12, p. 131, 2014.

[25] G. Gu, Z. Wu, Z. Zhang, and F. Qing, "Tribological properties of fluorine-containing additives of silicone oil," Tribology International, vol. 42, no. 3, pp. 397-402, 2009.

[26] D. R. Anderson and A. L. Smith, Analysis of Silicones, WileyInterscience, New York, NY, USA, 1974.

[27] M. D. Ninago, A. G. O. de Freitas, V. Hanazumi et al., "Synthesis of grafted block copolymers based on $\varepsilon$-caprolactone: influence of branches on their thermal behavior," Macromolecular Chemistry and Physics, vol. 216, no. 24, pp. 2331-2343, 2015.

[28] M. D. Ninago, A. E. Ciolino, M. A. Villar, A. G. O. de Freitas, P. I. R. Muraro, and C. Giacomelli, "Thermal characterization of "comb-like" block copolymers based on PCL obtained by combining ROP and RAFT polymerizations," Macromolecular Symposia, vol. 368, no. 1, pp. 84-92, 2016.

[29] M. D. Ninago, M. L. S. Marani, V. A. González et al., "Lithium naphthalenides in non-polar or in low-polarity media: some insights regarding their use as initiators in anionic polymerizations," Polymer Bulletin, vol. 74, no. 2, pp. 307-323, 2017.

[30] T. J. Hinton, A. Hudson, K. Pusch, A. Lee, and A. W. Feinberg, "3D printing PDMS elastomer in a hydrophilic support bath via freeform reversible embedding," ACS Biomaterials Science \& Engineering, vol. 2, no. 10, pp. 1781-1786, 2016.

[31] V. Ozbolat, M. Dey, B. Ayan, A. Povilianskas, M. C. Demirel, and I. T. Ozbolat, "3D printing of PDMS improves its mechanical and cell adhesion properties," ACS Biomaterials Science \& Engineering, vol. 4, no. 2, pp. 682-693, 2018.

[32] M. D. Ninago, A. J. Satti, A. E. Ciolino, and M. A. Villar, "Influence of amorphous block on the thermal behavior of well-defined block copolymers based on $\varepsilon$-caprolactone," Journal of Thermal Analysis and Calorimetry, vol. 112, no. 3, pp. 1277-1287, 2013.

[33] M. Lanfranconi, V. A. Alvarez, and L. N. Ludueña, "Isothermal crystallization of polycaprolactone/modified clay biodegradable nanocomposites," Journal of Thermal Analysis and Calorimetry, vol. 126, no. 3, pp. 1273-1280, 2016.
[34] A. T. Lorenzo, M. L. Arnal, J. Albuerne, and A. J. Müller, "DSC isothermal polymer crystallization kinetics measurements and the use of the Avrami equation to fit the data: guidelines to avoid common problems," Polymer Testing, vol. 26, no. 2, pp. 222-231, 2007.

[35] H. Liu, Y. Huang, L. Yuan et al., "Isothermal crystallization kinetics of modified bamboo cellulose/PCL composites," Carbohydrate Polymers, vol. 79, no. 3, pp. 513-519, 2010.

[36] P. U. Dhanvijay, V. V. Shertukde, and A. K. Kalkar, "Isothermal and nonisothermal crystallization kinetics of poly $(\varepsilon-$ caprolactone)," Journal of Applied Polymer Science, vol. 124, no. 2, pp. 1333-1343, 2012.

[37] N. Hadjichristidis, H. Iatrou, S. Pispas, and M. Pitsikalis, "Anionic polymerization: high vacuum techniques," Journal of Polymer Science Part A: Polymer Chemistry, vol. 38, no. 18, pp. 3211-3234, 2000.

[38] A. E. Ciolino, M. A. Villar, E. M. Vallés, and N. Hadjichristidis, "Synthesis and characterization of model polybutadiene-1, 4b-polydimethylsiloxane-b-polybutadiene-1, 4 copolymers," Journal of Polymer Science Part A: Polymer Chemistry, vol. 45, no. 13, pp. 2726-2733, 2007.

[39] M. D. Ninago, A. J. Satti, J. A. Ressia et al., "Self-assembly of well-defined PS-b-PDMS copolymers in bulk and in selective solvent," Chemical Engineering Transactions, vol. 17, pp. 1807-1811, 2009.

[40] M. D. Ninago, A. J. Satti, J. A. Ressia, A. E. Ciolino, M. A. Villar, and E. M. Vallés, "Controlled synthesis of poly (dimethylsiloxane) homopolymers using high-vacuum anionic polymerization techniques," Journal of Polymer Science Part A: Polymer Chemistry, vol. 47, no. 18, pp. 47744783, 2009.

[41] M. D. Ninago, A. J. Satti, A. E. Ciolino et al., "Synthesis and morphology of model PS-b-PDMS copolymers," Journal of Polymer Science Part A: Polymer Chemistry, vol. 48, no. 14, pp. 3119-3127, 2010.

[42] A. J. Satti, A. G. O. de Freitas, M. L. S. Marani et al., “Anionic ring opening polymerization of $\varepsilon$-caprolactone initiated by lithium silanolates," Australian Journal of Chemistry, vol. 70, no. 1, pp. 106-112, 2017.

[43] W. Yuan, J. Yuan, F. Zhang, X. Xie, and C. Pan, "Synthesis, characterization, crystalline morphologies, and hydrophilicity of brush copolymers with double crystallizable side chains," Macromolecules, vol. 40, no. 25, pp. 9094-9102, 2007.

[44] J. Skey and R. K. O’Reilly, "Facile one pot synthesis of a range of reversible addition-fragmentation chain transfer (RAFT) agents," Chemical Communications, no. 35, pp. 4183-4185, 2008.

[45] J. Brandrup, E. H. Immergut, and E. A. Grulke, Polymer Handbook, Wiley, New York, NY, USA, 4th edition, 1999.

[46] T. Hamaide, M. Pantiru, H. Fessi, and P. Boullanger, "Ringopening polymerisation of $\varepsilon$-caprolactone with monosaccharides as transfer agents. A novel route to functionalised nanoparticles," Macromolecular Rapid Communications, vol. 22, no. 9, pp. 659-663, 2001.

[47] H. Sun, L. Mei, C. Song, X. Cui, and P. Wang, "The in vivo degradation, absorption and excretion of PCL-based implant," Biomaterials, vol. 27, no. 9, pp. 1735-1740, 2006.

[48] S. G. Nanaki, G. Z. Papageorgiou, and D. N. Bikiaris, "Crystallization of novel poly ( $\varepsilon$-caprolactone)-block-poly (propylene adipate) copolymers," Journal of Thermal Analysis and Calorimetry, vol. 108, no. 2, pp. 633-645, 2012. 
[49] W. Phetwarotai and D. Aht-Ong, "Isothermal crystallization behaviors and kinetics of nucleated polylactide/poly (butylene adipate-co-terephthalate) blend films with talc," Journal of Thermal Analysis and Calorimetry, vol. 126, no. 3, pp. 17971808, 2016.

[50] N. Wu, L. Huang, and A. Zheng, "Synthesis and properties of polystyrene/polydimethylsiloxane graft copolymers," Frontiers of Chemistry in China, vol. 1, no. 3, pp. 350-356, 2006.

[51] N. Sahiner and S. Demirci, "The use of graphene oxideembedded superporous poly (2-hydroxyethylmethacrylate) cryogels for $\mathrm{p}$ (aniline) conductive polymer synthesis and their use in sensor applications," Materials \& Design, vol. 120, pp. 47-55, 2017.

[52] S. H. Hyon, K. Jamshidi, and Y. Ikada, "Synthesis of polylactides with different molecular weights," Biomaterials, vol. 18, no. 22, pp. 1503-1508, 1997.

[53] R. F. Storey and J. W. Sherman, "Kinetics and mechanism of the stannous octoate-catalyzed bulk polymerization of $\varepsilon$-caprolactone," Macromolecules, vol. 35, no. 5, pp. 1504-1512, 2002.

[54] J. Choi, S. W. Chun, and S. Y. Kwak, "Non-isothermal crystallization of hyperbranched poly( $\varepsilon$-caprolactone)s and their linear counterpart," Macromolecular Chemistry and Physics, vol. 207, no. 13, pp. 1166-1173, 2006.

[55] N. A. Peppas, "Poly (2-hydroxyethyl methacrylate)," Polymer Data Handbook, pp. 598-599, 1999.

[56] G. Siqueira, C. Fraschini, J. Bras, A. Dufresne, R. Prud'homme, and M. P. Laborie, "Impact of the nature and shape of cellulosic nanoparticles on the isothermal crystallization kinetics of poly (E-caprolactone)," European Polymer Journal, vol. 47, no. 12, pp. 2216-2227, 2011.

[57] A. J. Lovinger, B. J. Han, F. J. Padden, and P. A. Mirau, "Morphology and properties of polycaprolactone-poly (dimethyl siloxane)-polycaprolactone triblock copolymers," Journal of Polymer Science Part B: Polymer Physics, vol. 31, no. 2, pp. 115-123, 1993.

[58] J. Cai, M. Liu, L. Wang, K. Yao, S. Li, and H. Xiong, "Isothermal crystallization kinetics of thermoplastic starch/poly (lactic acid) composites," Carbohydrate Polymers, vol. 86, no. 2, pp. 941-947, 2011.

[59] J. Cai, Z. Xiong, M. Zhou et al., "Thermal properties and crystallization behavior of thermoplastic starch/poly ( $\varepsilon$-caprolactone) composites," Carbohydrate Polymers, vol. 102, pp. 746-754, 2014.

[60] M. D. Ninago, O. V. López, M. M. S. Lencina et al., "Enhancement of thermoplastic starch final properties by blending with poly (E-caprolactone)," Carbohydrate Polymers, vol. 134, pp. 205-212, 2015.

[61] O. Persenaire, M. Alexandre, P. Degée, and P. Dubois, "Mechanisms and kinetics of thermal degradation of poly ( $\varepsilon$-caprolactone)," Biomacromolecules, vol. 2, no. 1, pp. 288-294, 2001.

[62] A. G. P. R. Figueiredo, A. R. P. Figueiredo, A. Alonso-Varona et al., "Biocompatible bacterial cellulose-poly (2-hydroxyethyl methacrylate) nanocomposite films," BioMed Research International, vol. 2013, Article ID 698141, 14 pages, 2013.

[63] G. Gorrasi, L. Vertuccio, L. Annunziata, C. Pellecchia, and D. Pappalardo, "Correlations between microstructural characterization and thermal properties of well defined poly( $\varepsilon$-caprolactone) samples by ring opening polymerization with neutral and cationic bis(2,4,6-triisopropylphenyl)tin(IV) compounds," Reactive and Functional Polymers, vol. 70, no. 3, pp. 151-158, 2010. 


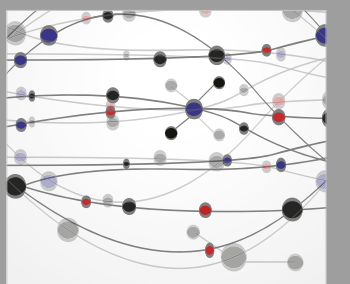

The Scientific World Journal
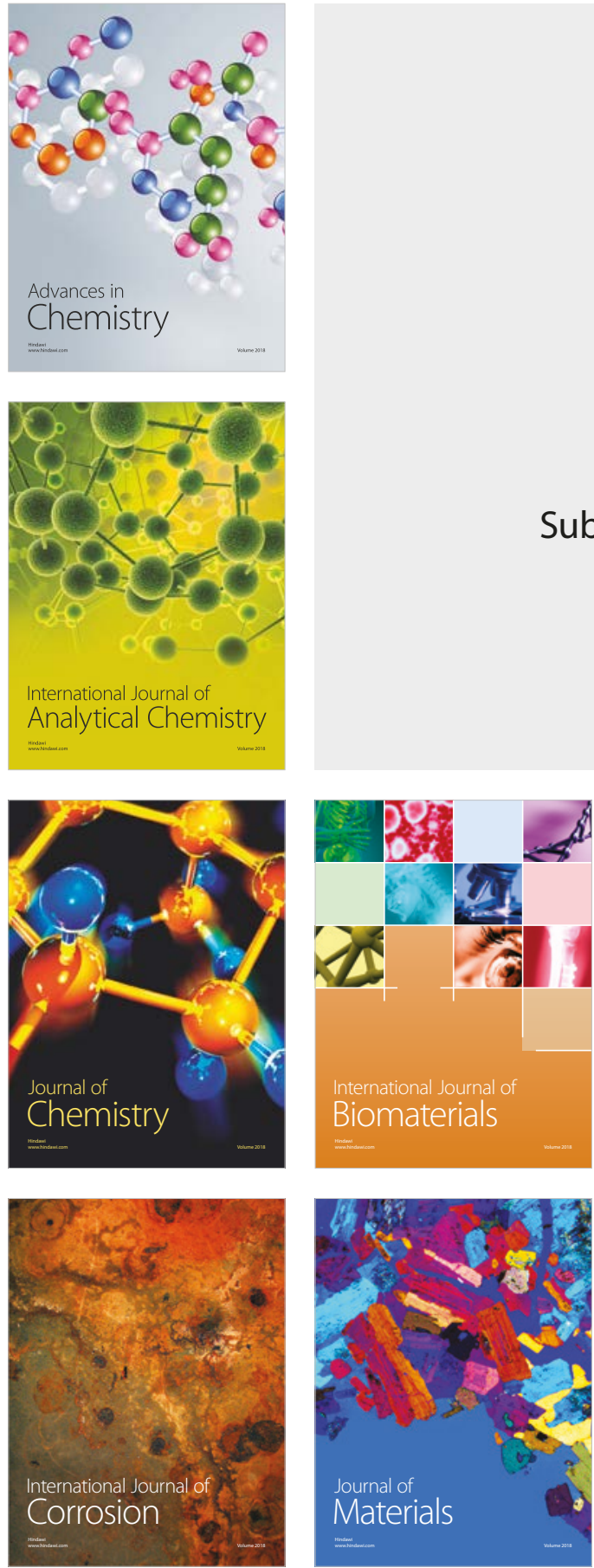

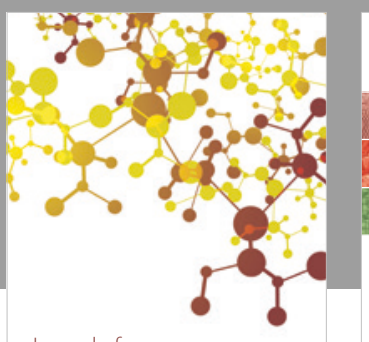

Journal of

Applied Chemistry
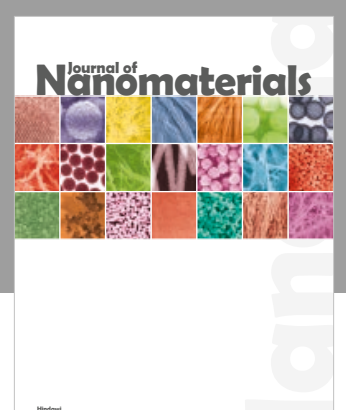

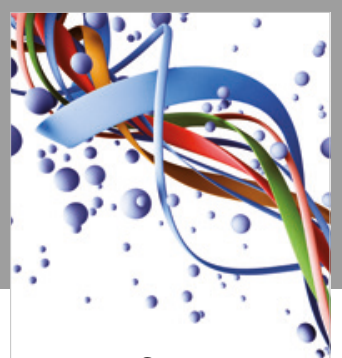

Scientifica

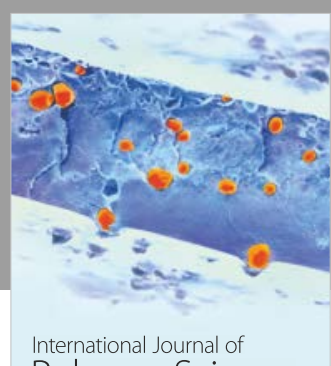

Polymer Science

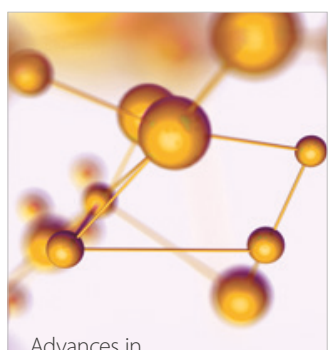

Physical Chemistry
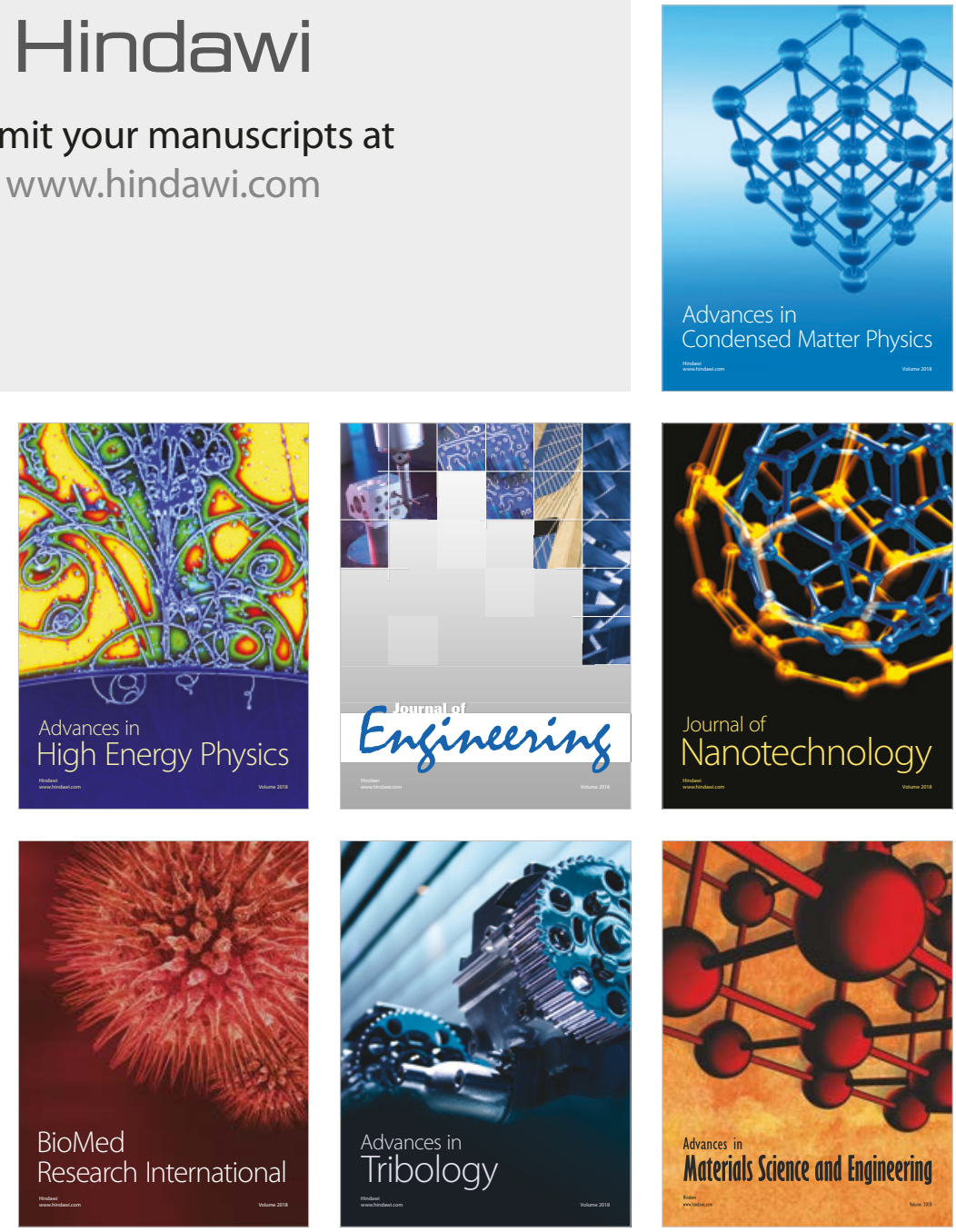